\title{
The costs of illiteracy in South Africa
}

\author{
MARTIN GUSTAFSSON, SERVAAS VAN DER BERG, DEBRA SHEPHERD AND COBUS \\ BURGER
}

Stellenbosch Economic Working Papers: 14/10
KEYWORDS: LITERACY, ILLITERACY, SOUTH AFRICA, EDUCATION PRODUCTION FUNCTION, ECONOMIC GROWTH JEL: C35, D23, I28, O15

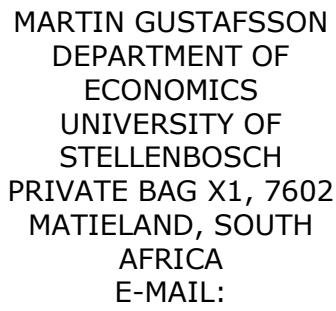

MGUSTAFSSON@SUN.AC

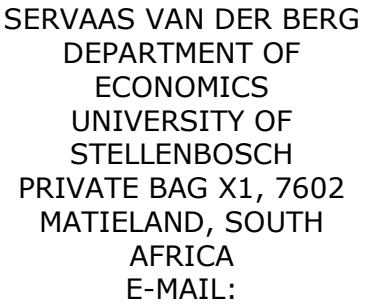
DEPARTMENT OF ECONOMICS UNIVERSITY OF STELLENBOSCH PRIVATE BAG X1, 7602 MATIELAND, SOUTH AFRICA E-MAIL: SVDB@SUN.AC.ZA

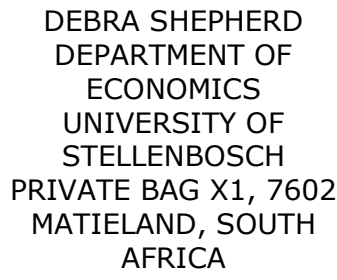

C.ZA
COBUS BURGER DEPARTMENT OF ECONOMICS

UNIVERSITY OF

STELLENBOSCH PRIVATE BAG X1, 7602 MATIELAND, SOUTH AFRICA E-MAIL:

COBUSBURGER@SUN.AC. ZA

A WORKING PAPER OF THE DEPARTMENT OF ECONOMICS AND THE BUREAU FOR ECONOMIC RESEARCH AT THE UNIVERSITY OF STELLENBOSCH 


\section{The costs of illiteracy in South Africa ${ }^{1}$ \\ MARTIN GUSTAFSSON, SERVAAS VAN DER BERG, DEBRA SHEPHERD AND COBUS BURGER}

\section{ABSTRACT}

In South Africa there has been a surge in publicly funded adult literacy education in recent years. There is a recognition that for the effective monitoring of adult literacy, direct measures of literacy are required. Grade attainment, self-reported ability to read and behavioural variables relating to, for instance, reading habits produce vastly different measures of adult literacy in South Africa. It is noteworthy that self-reported values change over time as people's perceptions of what consitutes literacy shifts. A 75\% literacy rate is arguably a plausible figure, though the absence of a direct measure is problematic. An education production function suggests that literacy-related parent behaviour, independently of parent years of education, influences performance of learners in school. In a multivariate employment model, self-reported literacy is a statistically significant predictor of being employed. In a cross-country growth model, poor quality schooling emerges as the variable requiring the most urgent policy attention to sustain and improve South Africa's economic development. Both microeconomic and macroeconomic estimates suggest that with a more typical level of school performance South Africa's GDP would be $23 \%$ to $30 \%$ higher than it currently is.

Keywords: Literacy, Illiteracy, South Africa, Education production function, Economic growth

JEL codes: C35, D23, I28, O15

\footnotetext{
${ }^{1}$ This report was produced for JET Education Services in 2009 and was made possible by funding provided by Nedbank.
} 


\section{An extended summary of the findings}

The paper's key concerns are to estimate the current level of illiteracy in South Africa and to gauge the costs of illiteracy, in monetary and non-monetary terms, to individuals and to the country. Moreover, the paper identifies key strategies with respect to data collection and education that seem important in the fight against illiteracy in South Africa.

In section 2 the UN and South African policy backgrounds are discussed. Both globally and in South Africa, public commitment towards eradicating adult illiteracy has been strong, and recently concrete targets have been set. But at both levels there has been insufficient clarity around defining and measuring illiteracy, which one can assume affects adversely proper monitoring of programme effectiveness. The trend has been for either grade attainment or self-reported ability to read and write to be used as proxies for more objective measures of literacy. Internationally, methodological advances have been made in adult literacy monitoring programmes such as IALS, ALL and LAMP, but the implementation of these kinds of programmes has not been widespread (they have enjoyed much less success than standardised testing programmes aimed at schools). South Africa's recently launched Kha ri Gude adult education programme is briefly discussed. This is an ambitious programme, which aims to halve adult illiteracy by 2012 , has expanded phenomenally in just two years to an enrolment of around 620,000, and includes student assessment tools that follow the LAMP approach.

Section 3 provides a short literature review. Within the microeconomic field, there is a contradiction between the typical finding for most countries whereby the rates of return to primary schooling exceed those of the other levels, and the finding in South Africa that below the end of secondary schooling, each additional grade makes little difference to one's earnings. It is suggested that the South African pattern is the product of an unusual emphasis on a single standardised qualification at the end of Grade 12, and that given the existence of national qualifications below the Grade 12 level, the typical pattern of high returns to primary schooling might have emerged. On the macroeconomic side, there has been an important shift of emphasis in recent years, from the use of years of schooling as a proxy for human capital in explaining economic growth, to the use of educational quality variables. This shift has emphasised the relative unimportance of quantitative measures of education (such as years of schooling), and the relative importance of qualitative test-based measures. This has profound education policy implications. Human capital, including literacy, should largely be viewed in qualitative terms (for instance on the basis of standardised assessments), and not quantitative terms (for instance years of schooling). Focussing exclusively on quantitative measures can result in poorly aligned policies.

Section 4 concentrates on the level of illiteracy amongst adults in South Africa. Published adult literacy rates for the country vary enormously, from the $88 \%$ of UNESCO to an extremely pessimistic rate of $7 \%$ based on imputations using the level of learner performance in schools. The self-reported ability to read and write variable collected by Stats SA results in an adult literacy rate of $90 \%$. All commonly employed grade attainment criteria result in lower rates, from around $84 \%$ if Grade 4 (a UNESCO standard) is used to $78 \%$ or $71 \%$ if Grades 6 or 7 (common standards in South Africa) are used. An interesting alternative to the self-reported literacy and grade attainment criteria is the use of behavioural criteria, such as time spent reading per week. Data collected from the parents of learners suggest that at least $75 \%$ of adults spend at least an hour reading per week. It is perhaps useful to think of this $75 \%$ level as a plausible minimum literacy level in South Africa.

Some interrogation of cross-country data indicates that having self-reported rates which are higher than rates linked to grade attainment is the norm for developing countries, suggesting that self-reported rates universally tend to result in over-estimates of adult literacy. A further problem with self-reported literacy is that values are unstable over time. In the period 2001 to 
2007, South African adults have clearly become more stringent in their self-assessment of their level of literacy, resulting in the curious phenomenon of a declining adult literacy rate, if one uses the self-reported variable. Despite these limitations, policy relevant conclusions can be drawn from this variable, such as that minority African language speakers deserve priority in the targeting of adult education due to their lower than average level of literacy, a pattern possibly resulting from the unavailability of textbooks in certain languages in the past.

There seems to be no good reason for not implementing a periodic sample-based testing of adults in South Africa to obtain more reliable adult literacy rates. Such data gathering would be inexpensive relative to the cost of adult education programmes, and would assist in understanding how the country's human capital contributes towards growth and development. This would moreover provide South Africa with the opportunity to be an innovator in this area, given the paucity of reliable adult literacy data across virtually all developing countries. Until we obtain better data, the Grade 6 or Grade 7 criteria currently used in South Africa are probably optimal for planning purposes. In particular, the Grade 7 criterion appears to offer a 'safe' option insofar as very few South Africans with at least this level of education regard themselves as illiterate.

In section 5, the effect of literacy at the individual level is explored through, firstly, an education production function focussing especially on parent education and behaviour and, secondly, a multivariate model exploring the link between literacy and employment. The production function, which uses South Africa's 2006 PIRLS data, suggests there are strong parent effects on learner performance, which appear to surpass commonly cited schools-based factors such as free school lunches and parent-teacher meetings. Parent education makes a difference, but so does literacy-related parent behaviour, such as reading. It is noteworthy that when learners, including historically disadvantaged learners, spend much time watching television or playing computer games (factors over which parents arguably have some control), reading scores appear to decline. In the employment model, self-reported literacy is a statistically significant predictor of one's probability of being employed, suggesting that targeting and selection strategies in adult education programmes should take self-assessment (and not just grade attainment) into account.

Section 6 explores the linkages between literacy and people's values, using the South African records from the 2005 World Values Survey collection. Whilst the benefits of being literate are perhaps smaller than one would have expected, those who are literate feel healthier, and are generally more satisfied with life, than those who are not. Literacy is moreover associated with a greater tendency to find fault in the state, and in political parties, something which can be regarded as necessary in a nascent democracy where these institutions require ongoing improvement. Most of the section focuses on using a standard cross-country growth model to establish South Africa's position in the education-growth equation, and to estimate a cost associated with not having a more literate population. The model separates the presence of lower level human capital (measured using Grade 5 PIRLS results) from higher level human capital (proxied by an academic publications measure). It is concluded that of five factors explaining economic growth (the two qualitative human capital measures, a quantitative secondary level enrolment variable, the decline in population growth, and investment in the economy), poor quality schooling at the primary level is the variable requiring the most urgent attention in South Africa's development planning. This quality variable deserves far more attention than the other schooling variable, the secondary school gross enrolment ratio. It is estimated that if the quality of schooling in South Africa were where it should be (at a level befitting a middle income country), GDP would be R550 billion higher than it currently is, or $23 \%$ above the current level. Whilst these figures are clearly sensitive to the underlying assumptions (we tested an alternative microeconomic model, and that gives us a higher $30 \%$ value), poor quality schooling at the primary level, which increases adult illiteracy in future decades, is undoubtedly a large, and arguably the largest, inhibitor of South Africa's growth and development. 
A simplified version of the graph presented in the paper to explain the growth model appears below.

Figure 1: Country development and school performance

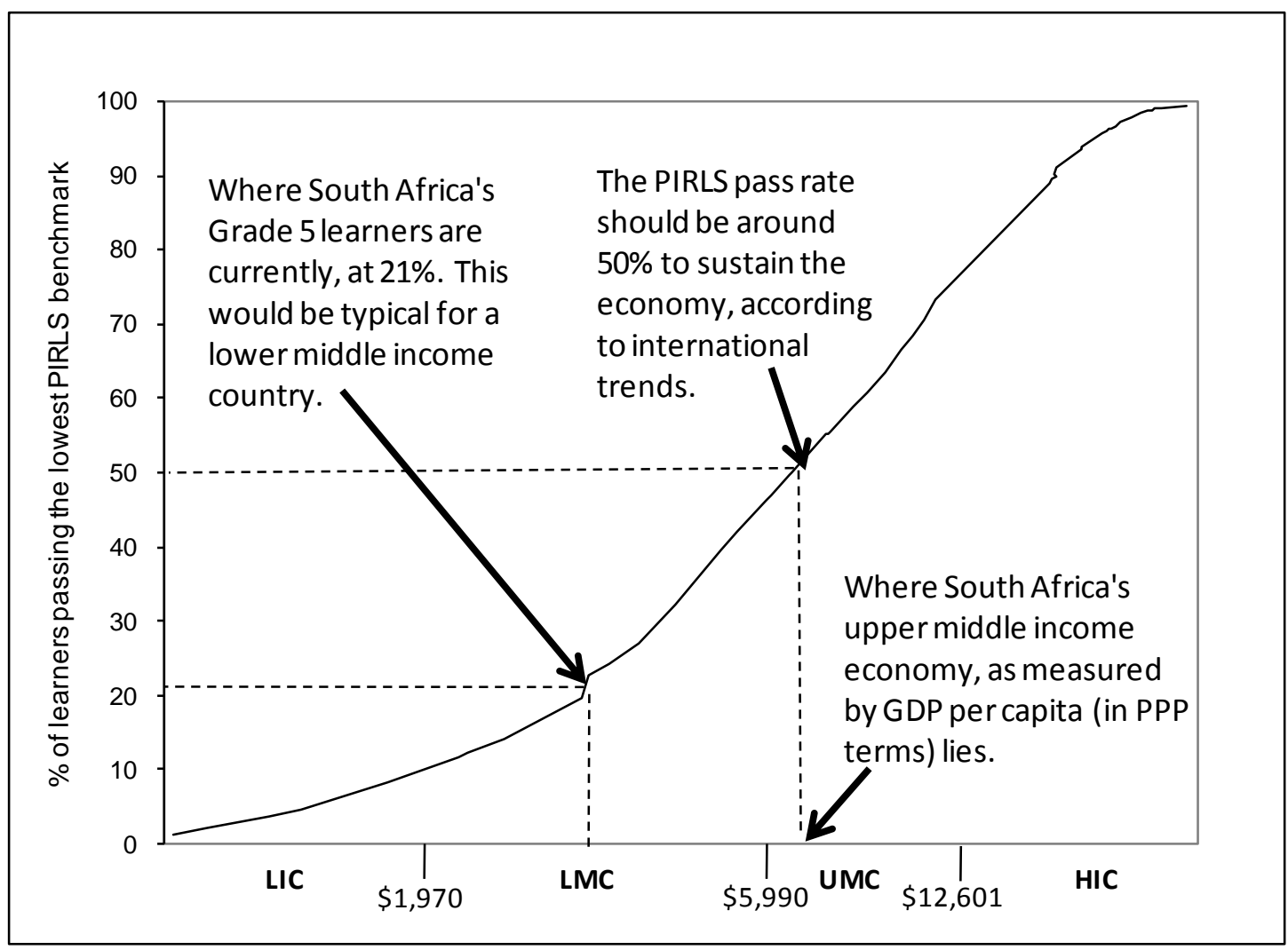




\section{Acronyms and abbreviations used}

$\begin{array}{ll}\text { ALL } & \text { Adult Literacy and Lifeskills Survey } \\ \text { ASGISA } & \text { Accelerated and Shared Growth - South Africa } \\ \text { EFA } & \text { Education for All } \\ \text { GDP } & \text { Gross domestic product } \\ \text { GER } & \text { Gross enrolment ratio } \\ \text { GHS } & \text { General Household Survey } \\ \text { HIC } & \text { High income country } \\ \text { IALS } & \text { International Adult Literacy Survey } \\ \text { ISO } & \text { International Organization for Standardization } \\ \text { LAMP } & \text { Literacy Assessment and Monitoring Programme } \\ \text { LFS } & \text { Labour Force Survey } \\ \text { LIC } & \text { Low income country } \\ \text { LMC } & \text { Lower middle income country } \\ \text { NGO } & \text { Non-government organisation } \\ \text { OECD } & \text { Organisation for Economic Co-operation and Development } \\ \text { OLS } & \text { Ordinary least squares } \\ \text { PIRLS } & \text { Progress in International Reading Literacy Study } \\ \text { RDP } & \text { Reconstruction and Development Programme } \\ \text { SACMEQ } & \text { Southern and Eastern Africa Consortium for Monitoring Educational Quality } \\ \text { SES } & \text { Socio-economic status } \\ \text { Stats SA } & \text { Statistics South Africa } \\ \text { TIMSS } & \text { Trends in International Mathematics and Science Study } \\ \text { UIS } & \text { UNESCO Institute for Statistics } \\ \text { UMC } & \text { Upper middle income country } \\ \text { UN } & \text { United Nations } \\ \text { UNDP } & \text { United Nations Development Programme } \\ \text { UNESCO } & \text { United Nations Educational, Scientific and Cultural Organization } \\ \text { US } & \text { United States }\end{array}$

The following abbreviations for the provinces were used:

$\begin{array}{ll}\text { EC } & \text { Eastern Cape } \\ \text { FS } & \text { Free State } \\ \text { GP } & \text { Gauteng } \\ \text { KN } & \text { KwaZulu-Natal } \\ \text { LP } & \text { Limpopo } \\ \text { MP } & \text { Mpumalanga } \\ \text { NC } & \text { Northern Cape } \\ \text { NW } & \text { North West } \\ \text { WC } & \text { Western Cape }\end{array}$

ISO three-letter codes for countries are listed in Appendix B (the codes for Lesotho and Swaziland are LSO and SWZ). 


\section{Introduction}

Illiteracy is rightly seen as a major social scourge. The Nobel economics laureate Amartya Sen, in his Development as Freedom, identifies illiteracy, premature mortality and undernourishment as the three factors most succinctly describing human deprivation at the most basic level ${ }^{2}$.

This paper attempts to throw new light on the challenges and solutions surrounding illiteracy in South Africa. Our focus is shaped by the following three questions:

- What are the long term consequences of low literacy levels, for the individual and society as whole?

- What is the Rand value cost of having low literacy levels in the country?

- What are the levels of literacy in the country?

These questions deal mainly with the nature of the problem in South Africa. Whilst we do examine the problem in depth, we also pay attention to the policy and behavioural solutions that can contribute towards a South Africa that is free from illiteracy.

The available data sources for answering the three questions are far from ideal, and we discuss the limitations with these sources in some depth. At the same time, we believe that the existing datasets have not been sufficiently explored, and that the new analysis we undertake using the available data can contribute towards a clearer picture of the challenges. Moreover, examining what data we have assists in identifying the gaps, and hence planning the collection of better data in the future.

In the paper, we use a number of different definitions and criteria for literacy, partly because the data force us to do this, and partly because literacy needs to be understood differently depending on one's focus (in particular one's policy focus).

The paper proceeds as follows:

- Section 2 looks at how the UN bodies and the South African government have dealt with illiteracy in their policies, and what the assumptions behind these policies have been.

- Section 3 provides a literature review with a focus on the economic literature dealing with the relationship between illiteracy, on the one hand, and individual and national welfare, on the other.

- Section 4 presents a cautious analysis of the available data to provide a picture of the levels of illiteracy in South Africa. Definitions of illiteracy, and some cross-country comparisons, are discussed. The data used here are mainly the Labour Force Survey datasets of Stats SA (over the 2001 to 2007 period), but PIRLS data on parents are also used to provide an alternative view.

- Section 5 examines the impact of illiteracy at the level of individuals in South Africa. This is done from two angles. Firstly, the impact of parent education on the performance of children in schools is examined, through a production function using PIRLS data. Secondly, the relationship between illiteracy (and basic education) on the one hand, and employment on the other, receives attention, through a multivariate modelling of Labour Force Survey data.

\footnotetext{
${ }^{2}$ Sen, 1999: 103 .
} 
- Section 6, after examining briefly links between literacy and people's values (using the South African records from the World Values Survey dataset), turns to the monetary cost of having the levels of illiteracy we have, using a cross-country growth model. For the measurement of literacy, this modelling makes use of the PIRLS 2006 dataset.

- Section 7 provides a conclusion.

Whilst the paper examines the costs to individuals and the country of not reducing illiteracy (or, to put it differently, the benefits of reducing it), it does not examine the costs of literacy enhancing activities such as adult education programmes and school improvement initiatives. This falls beyond the brief of this paper. It is worth pointing out, however, that these monetary costs are considered to be low, at least for a country like South Africa, which already devotes a high level of public and private spending towards education. The literature indicates that worldwide the cost of providing basic education to illiterate adults is not high, and that given relatively certain benefits (depending, of course, on the design of the programme), costs relative to benefits are remarkably $l_{0}{ }^{3}$. As far as school improvement initiatives are concerned, better utilisation of existing education funding has been argued is the key to quality improvements, rather than higher levels of funding (at least in South Africa) ${ }^{4}$. There is undoubtedly a sound argument in South Africa for increasing spending on adult basic education programmes. However, the magnitude of this need is small in terms of government's overall budget. Whether one increases the budget for adult education through growth in the total education budget, or by diverting some budget away from schooling, the impact is negligible. In fact, it could be argued that since the advent of democracy in 1994, the core problem has not been under-budgeting in adult education, but delays in formulating a sufficiently clear and convincing strategy that could attract the necessary public funding.

\footnotetext{
${ }^{3}$ UNESCO, 2005b: 145.

${ }^{4}$ Gustafsson and Patel, 2006.
} 


\section{The policy background}

This section describes how global and South African policies tackle the problem of adult illiteracy, and examines the information and assumptions underlying the policy. The vast terrain of policies for improving educational quality in schools, though linked to adult literacy, are not dealt with here, though there is some discussion of this topic in section 6 .

The role of the United Nations in bringing adult literacy issues to the fore has been substantial, and in many senses the UN has become a standards setter not just for the definitions of literacy, but even the design of adult education programmes. The 1948 Universal Declaration of Human Rights declared 'elementary education' a human right, adding that it should be free and compulsory. The right to literacy is implied, and the Declaration furthermore indicates that basic education should promote desirable values such as respect for human rights and a striving for world peace.

It was only in 1990, however, that UNESCO made an explicit commitment to advancing adult literacy, in the Jomtien World Declaration of Education for All ${ }^{5}$. We focus on the later Dakar Framework for Action, of 2000, which included more specifics on adult literacy. Goal 4 of the 2000 framework calls for 'Achieving a 50 per cent improvement in levels of adult literacy by 2015, especially for women, and equitable access to basic and continuing education for all adults'. Complementary goals are Goal 2 (getting all children to complete primary schooling by 2015) and goal 6 (ensuring that all children acquire 'literacy, numeracy and essential life skills') ${ }^{6}$.

Literacy rates of $85 \%$ for men and $74 \%$ for women worldwide were explicitly assumed. For developing countries, where the bulk of the problem lies, these figures are mostly derived through one of two approaches. Either national surveys which ask respondents whether they are able to read are used (this is the preferred approach as far as UNESCO is concerned) or, failing that, enrolment statistics submitted over the years to UNESCO are run through UNESCO's Global Age-specific Literacy Projections model, to arrive at an imputed literacy rate. As an example, in the 2009 Education for All Global Monitoring Report, out of 40 African countries with adult literacy rates, 18 had rates based on self-reported values. As we shall see below, both approaches are flawed.

The UNESCO argument for reducing adult illiteracy is sound, and is supported by the literature. The impact of literacy on the economic and social improvement of individuals is acknowledged, with special emphasis on the matter of female literacy, which is known to improve health in households, and better enrolment ratios for girls.

The weakness of the Dakar framework lies in the absence of direction with respect to defining literacy, measuring literacy and monitoring improvements. Goal 4 itself is vague as it is not clear what the $50 \%$ improvement refers to. Is it a $50 \%$ reduction in the number of illiterates, or an improvement in the literacy rate of $50 \%$, for instance? Guidance on how to deal with the typical problems experienced in adult basic education programmes is also absent.

Some of the gaps in the Dakar framework have been dealt with in the various releases of the EFA Global Monitoring Report?. The 2005 report elaborates extensively on goal 6 (the educational quality goal) and the 2007 report emphasises the importance of rigorous learner assessments in cross-country programmes such as SACMEQ and PIRLS, and in countryspecific 'national assessments' (the report provides a short account of these assessments by country). The 2006 report pays special attention to adult literacy, and discusses how

\footnotetext{
${ }^{5}$ UNESCO, 1990.

${ }^{6}$ UNESCO, 2000.

${ }^{7}$ See in particular UNESCO (2005a), UNESCO (2005b) and UNESCO (2006).
} 
measurement can be improved, with some attention to the experiences of three key programmes: IALS, ALL and LAMP.

The International Adult Literacy Survey (IALS) started in 1994 and has involved 21 countries, one of which, Chile, is a developing country. The IALS was the first ever attempt to obtain standardised test-based literacy figures from several countries. Data were collected from national samples, and apart from literacy, numeracy and problem-solving skills were tested. After 1998, following critiques of the tests, the sampling methodology, and the survey procedures, the IALS was revised and became the Adult Literacy and Lifeskills Survey (ALL). ALL has only seen six countries involved to date ${ }^{8}$.

The Literacy Assessment and Monitoring Programme (LAMP), started by the UNESCO Institute for Statistics (UIS) in around 2005, is largely aimed at introducing IALS-type literacy surveys in developing countries. A detailed methodology has been developed ${ }^{9}$, and the focus has been on piloting this in five countries: Mongolia, Morocco, Niger, Kenya and Jamaica. In 2007, Kenya published the results for the first survey, and the Kenyan experience is generally considered an important milestone for this kind of work in developing countries ${ }^{10}$.

Clearly, interest in measuring adult literacy in a standardised manner lags behind the interest in measuring learner performance in schools in programmes such as TIMSS (47 countries in total in 2003, of which 20 are developing countries). With a very few exceptions, such as Kenya, this kind of measurement is still extremely rare.

It is noteworthy that despite its focus on emerging improvements in the measurement of adult literacy, the 2006 EFA report stops short of questioning the worldwide literacy rate of around $80 \%$, or proposing how revisions of these estimates could be arrived at.

In South Africa, the government's Tirisano programme for improving education, launched in 1999, included as priority 2 of 9: 'We must break the back of illiteracy among adults and youths in five years, ${ }^{11}$. However, the implied large-scale adult literacy programme did not materialise. In 2008, a national government programme dealing specifically with adult literacy, Kha ri Gude, was launched ${ }^{12}$. The aim of the programme is to make 4.7 million adult literate between 2008 and 2012, the assumption being that this is more or less half of the total number of illiterate adults (and that this would achieve South Africa's compliance with the Dakar goal). The programme is premised on the employment of paid 'volunteers', the use of standardised teaching packs, and some partnering with NGOs within the structure of the public programme. Public spending is earmarked mainly for stipends for the volunteers, and free materials for students. Enrolment in Kha ri Gude was reported to be 360,000 in 2008, and preliminary Department of Education figures indicate an enrolment of around 620,000 in 2009, which exceeds original targets and can be seen as indicative of strong demand. Public spending by the national government in 2008 was around R470 million, resulting in around $\mathrm{R} 1,300$ per student, or more or less one-sixth of the level of spending on each public school learner ${ }^{13}$. Spending per student is expected to be reduced to around half of the 2008 figure in 2009 , largely through improved procurement processes relating to the student materials and some increases in the class sizes. Kha ri Gude, unlike many other literacy programmes, includes a standardised assessment component in which all students are assessed and results are moderated nationally. The assessment tools have been designed to be similar to those of

\footnotetext{
${ }^{8}$ Information obtained from the US National Center for Education Statistics

(http://nces.ed.gov/Surveys/ALL/index.asp).

${ }^{9}$ UNESCO, 2005c.

${ }^{10}$ See http://www.kenyadulteducation.org.

${ }^{11}$ Department of Education, 1999.

${ }^{12}$ See http://www.kharigude.co.za/.

${ }^{13}$ National Treasury, 2009: 258.
} 
UNESCO's LAMP. There is a strong emphasis on accountability mechanisms in the programme aimed at ensuring correct utilisation of the programme's resources.

The gaps at the international level with regard to definitions and clarity around measurement and monitoring processes have to a large degree been mirrored in South Africa ${ }^{14}$. In many ways Kha ri Gude represents a very serious attempt to deal with these gaps. However, a number of issues will need to be resolved as the programme unfolds. The assumption that there are around nine million illiterate adults in South Africa requiring assistance could be an over-estimate, given the discussion that follows in section 4. Though students are assessed in Kha ri Gude, how the overall effectiveness of the programme in improving the lives of people will be monitored is not yet finalised. In many respects literacy is a goal worth pursuing on its own, but based on the literature on the social effects of literacy it is also reasonable to expect results such as improved productivity and income, the empowerment of women and better health practices in the home. A common problem with adult literacy programmes is that they over-estimate demand. Enrolment levels in Kha ri Gude suggest this has not been the case, but it remains to be seen if the strong demand will persist. Though materials are free and the physical location of classes follows demand, there is likely to be a number of potential students who do not regard the benefits of literacy worth the cost and effort. Cost could include forfeited income in the case of the employed. Students are required to attend 10 hours of classes per week for 6 months, making a total of around 240 hours.

Unfortunately, in South Africa and elsewhere in the developing world, schooling is falling well short of expectations (as we shall see in section 6 below). The need to compensate for this failing through adult education is likely to continue for many decades to come. Success in the adult education field will to some extent depend on the right kind and level of attention to monitoring and programme evaluation in government, in NGOs and amongst researchers ${ }^{15}$.

\footnotetext{
${ }_{15}^{14}$ See Aitchison and Harley (2004).

${ }^{15}$ Oxenham (2004) provides an informative discussion of the 'evaluphobia' he believes often underlies the failure in adult education programmes.
} 


\section{What the literature says}

We repeat the three key questions dealt with in this report:

- What are the long term consequences of low literacy levels, for the individual and society as whole?

- What is the Rand value cost of having low literacy levels in the country?

- What are the levels of literacy in the country?

The first question is often asked in the literature, at the individual and country levels, as long as one does not make the presence of the word 'literacy' a requirement, as the question is often posed with respect to education in general. Sometimes, the reference to education is too general, as low-level educational outcomes (such as literacy) are not sufficiently distinguished from higher level outcomes (such as the ability to invent new technologies). This can be confusing, and requires some discrimination in the interpretation of the literature. The second question, a very specific one, is not answered with respect to any country to our knowledge, but it can be answered once one has answered the first one. The third question is such a basic one that one would think there would be a wealth of literature in this area across most countries. Unfortunately, this is not the case, in particular as far as developing countries are concerned, largely due to the data problems discussed in this paper.

In this section, we pay particular attention to studies dealing with the first question. We focus on the empirical findings in the literature, and not on the much more technical matter of methodology (section 6 deals with that to some degree). Given the overall focus of the paper, most of the literature we reviewed is from the field of economics.

We begin with the microeconomic literature dealing with the relationship between literacy (or basic education) and individual welfare (which is generally equated with income). Much of this literature is based on the Mincerian earnings function, a model that specifies that a range of factors, but in particular one's level of education and years of experience, predict what one will earn. Prominent here is the work of Psacharopoulos ${ }^{16}$, which has looked at rates of return at the primary, secondary and tertiary levels in a large number of countries, and emphasised that returns at the primary level are greatest, implying that developing countries ought to pay special attention to ensuring that everyone obtains a basic education (and achieves a basic level of literacy). The way this finding has been used has been criticised. In particular, ignoring investments at the secondary and tertiary levels in the interests of an almost exclusive emphasis on primary schooling is something development agencies such as the World Bank have been accused of at various points in time. But the finding itself has also been challenged, largely with reference to countries that display different patterns. South Africa is one such country. As Keswell and Poswell (2002) find, returns to schooling below the Grade 12 level are negligible. Though the causes behind this atypical pattern have not been studied in depth, it seems likely it results from South Africa's rather top-heavy and atypical qualifications system where there are no national qualifications issued below the Grade 12 level.

Very few earnings function analyses use data on actual literacy, skills or knowledge as a determinant of income. Mostly, the highest grade attained is used. A rare, albeit somewhat dated, exception is a study by Boissiere, Knight and Sabot (1985), who use a sample dataset of adults in Kenya and Tanzania to demonstrate the particularly powerful effects of literacy and numeracy, as measured through standardised tests, on productivity and income.

\footnotetext{
${ }^{16}$ See for instance Psacharopoulos and Patrinos (2002).
} 
A number of analysts explore the mechanisms whereby more education translates into better earnings. Here the argument often turns to the importance of having literate women, as this improves family planning, general health practices in the household, and the schooling of the next generation of females. A meta-study by Malhotra, Pande and Grown (2003) is a helpful source in this regard. Lauglo (2001) discusses the evidence of the impact of adult basic education programmes in Sub-Saharan Africa.

On the macroeconomic side, much attention since the 1960s has gone towards establishing the role of education, or human capital, in country growth models. One of the less complex examples is Mankiw, Romer and Weil's (1992) empirical model, which we use in section 6. Some models have used the self-reported literacy variable, for instance those of Romer (1989) and Naudé (2004), who focuses on Africa. Barro and Lee (2001) are amongst the few who have used test-based adult literacy statistics (from IALS) to link literacy to economic growth. Much of the complexity in some of the models is due to the attempt to explain how technological change, a strong predictor of growth, comes about, and how human capital, through imitation or innovation activities, contributes to technological change. Benhabib and Spiegel's (1994) empirical modelling, for example, pays special attention to how technological knowledge is disseminated across countries, and links this to trade and crosscountry learning. Given the technological changes in the last two decades, especially in the information and communication industries, these models emphasising the role of technology have enjoyed much prominence.

Recent work by Hanushek and Woessman (2007 and 2009) stands out as being particularly valuable for a number of reasons. They have made exceptionally good use of data from international testing programmes to arrive at educational quality measures, in contrast to the quantitative variables used in other growth modelling. They find, as one should expect, that measures of the quality of schooling are far more significant than measures of the quantity of schooling in the modelling of growth, and suggest that emphasising quantitative measures (such as years of schooling) can be fundamentally misleading for the policymaker. Hanushek and Woessman's approach, which is permitted by substantial improvements in recent years in the availability of qualitative data, has undoubtedly brought about an important shift in our understanding of growth and development. In their 2007 paper, Hanushek and Woessman underline three policy strategies. One, there should be healthy competition between schools, linked to the parent's right to choose a school. Two, there should be sufficient management autonomy at the school level. In other words, schools should not be entangled in a large bureaucracy. Three, there should be accountability for results amongst schools. It is interesting to gauge South African schools against these three criteria. Arguably, South Africa does well against the first two criteria, but poorly against the third one, largely because accountability mechanisms linked to results are insufficiently developed. This will receive attention below in section 6. An advantage with the Hanushek and Woessman papers is that they are easy to read, in comparison to other texts on the topic. Their economic models are relatively un-complex, and their policy discussion straightforward.

Some analysts have questioned certain fundamentals of the 'education produces growth' hypothesis. Bils and Klenow (2000), for instance, suggest that it is possible that with higher income comes the ability to invest more in education, and that this produces better educational quality. In other words, there could be reverse causality. Pritchett (1996), using empirical cross-country models, argues that educational quality cannot lie behind improvements in income, as more education does not appear to improve productivity. The responses to the sceptics have been convincing. As an example, Hanushek and Kimko (2000) compare the pay of US workers who received their schooling outside the US, to school quality levels from the countries of origin, and find a clear association, thus supporting the notion that education, and not other country-specific factors, lie behind better income. 


\section{Establishing literacy levels in South Africa}

How literate are South African adults? This question is the focus of this section. We first look at Stats SA household data, which are commonly used to address the question, and uncover a few unexpected patterns. We also explore other sources of data, arrive at tentative conclusions about the answer to the question, and explain what data would be required for greater certainty.

Stats SA's sample-based household surveys generally include the following questions, directed towards all household members: 'Can you read in at least one language?' and 'Can you write in at least one language?' The interviewer is told to consider the answer to be 'Yes' if the person can read (or write) a whole paragraph, but 'No' if, for instance, the person is just able to read (or write) his or her name. The questions are asked in both the Labour Force Survey (LFS) and General Household Survey (GHS). Here we use the LFS dataset, because this survey includes the language most often spoken at home, something the GHS does not include. Moreover, we examine the grade attainment data for adults included in the LFS.

Figure 2 illustrates the trend over time captured in the LFS (there are two surveys a year). The self-reported ability to read and write variables, and three grade attainment criteria are shown. Grade 4 is shown as UNESCO commonly uses a Grade 4 or 5 criterion $^{17}$, and Grade 6 and 7 are commonly used as criteria for being literate in South Africa ${ }^{18}$. The focus is on the population aged 15 and above, which follows the UNESCO standard ${ }^{19}$ (in South Africa age 16 and older is commonly used). Using grade attainment criteria for arriving at an adult literacy rate clearly results in lower rates in South Africa, compared to the self-reported variables. For instance, using the Grade 7 criterion gives a rate of around 70\%, against around $90 \%$ if one uses the self-reported variables. It makes virtually no difference to the selfreported measure whether one uses ability to read or ability to write. In fact, for $99.6 \%$ of adults, the response is the same. The grade-linked literacy rates are all improving. For instance, the Grade 6 criterion gives an annual improvement in the literacy rate of 0.5 percentage points (if we exclude the rate for 2001, which is an outlier that could represent an error in the data). On the other hand, self-reported literacy is declining very slightly by an average of 0.1 percentage point a year. This contradiction is puzzling. Below, we argue that South Africans appear to have become more stringent in their self-reporting of their literacy over the years.

The adult literacy rate for South Africa published by UNESCO in 2009, arrived at through running enrolment figures submitted over the years by the South African government through UNESCO's Age-specific Literacy Projections Model, is 88\%, in other words between the self-reported and Grade 4 curves in Figure $2^{20}$. This translates into around 3.9 million illiterate adults (out of a total of 33 million adults in 2007). Using the Grade 6 or 7 criteria results in much higher numbers of illiterate adults of around 7.8 million and 10.1 million.

\footnotetext{
${ }^{17}$ UNESCO, 2005b: 164.

${ }^{18}$ Department of Education (2006) specifies Grade 6, but Grade 7 is also commonly used as this is the last primary school grade.

${ }^{19}$ UNESCO, 2003.

${ }^{20}$ UNESCO, 2009: 274.
} 
Figure 2: Labour Force Survey literacy trend 2001-2007 (all adults)

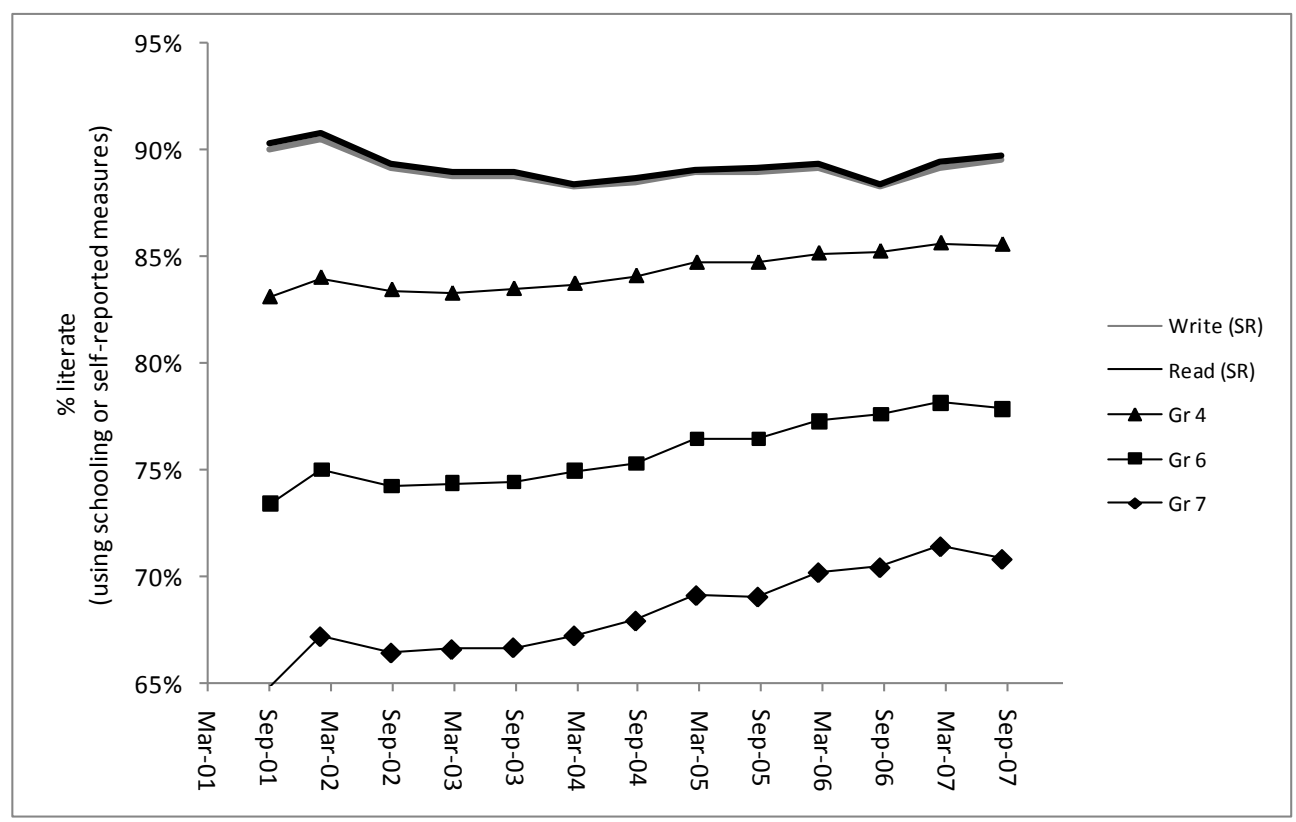

Source: Stats SA, 2007. Note: The 'Write (SR)' and 'Read (SR)' curves overlap almost perfectly, and are therefore not distinguishable. All adults aged 15 and above considered.

The next graph follows one set of age cohorts, namely those aged 15 to 50 in 2001 . This view of the trend is important as any improvements seen in the previous graph would to a large degree be the result of the fact that the younger cohorts entering the group of adults would tend to be better educated that those leaving. The Figure 3 view permits us to see what differences may have been brought about by educational interventions aimed at adults. Here the puzzle of a decline in self-reported literacy is more marked (the average annual decrease is 0.3 percentage points). The grade attainment improvements are less marked than the in the previous graph, but still noticeable, especially with respect to Grade 7 . However, the grade attainment improvements are limited to younger adults. If we examine only adults aged 25 and above, there is no noticeable improvement for any of the grades. This does not mean that there is no educational improvement at a basic level amongst adults. The way the LFS grade attainment questions are posed in the questionnaire makes it likely that that they will elicit responses only with respect to schooling, and not with respect to equivalent attainment within adult basic education. It should be noted, however, that only around $0.1 \%$ of adults, or around 50,000 , indicated in the LFS that they were attending adult education classes, and this level does not seem to have changed noticeably in either direction between 2001 and 2007. Such low levels of participation in adult education would not be associated with noteworthy changes in the overall adult literacy figures. Even if 25,000 adults had achieved a Grade 7 level each year in the 2001 to 2007 period, this would only have changed the adult literacy rate (using the Grade 7 criterion) by around 0.05 percentage points per year. 
Figure 3: Labour Force Survey literacy trend 2001-2007 (fixed cohort of adults)

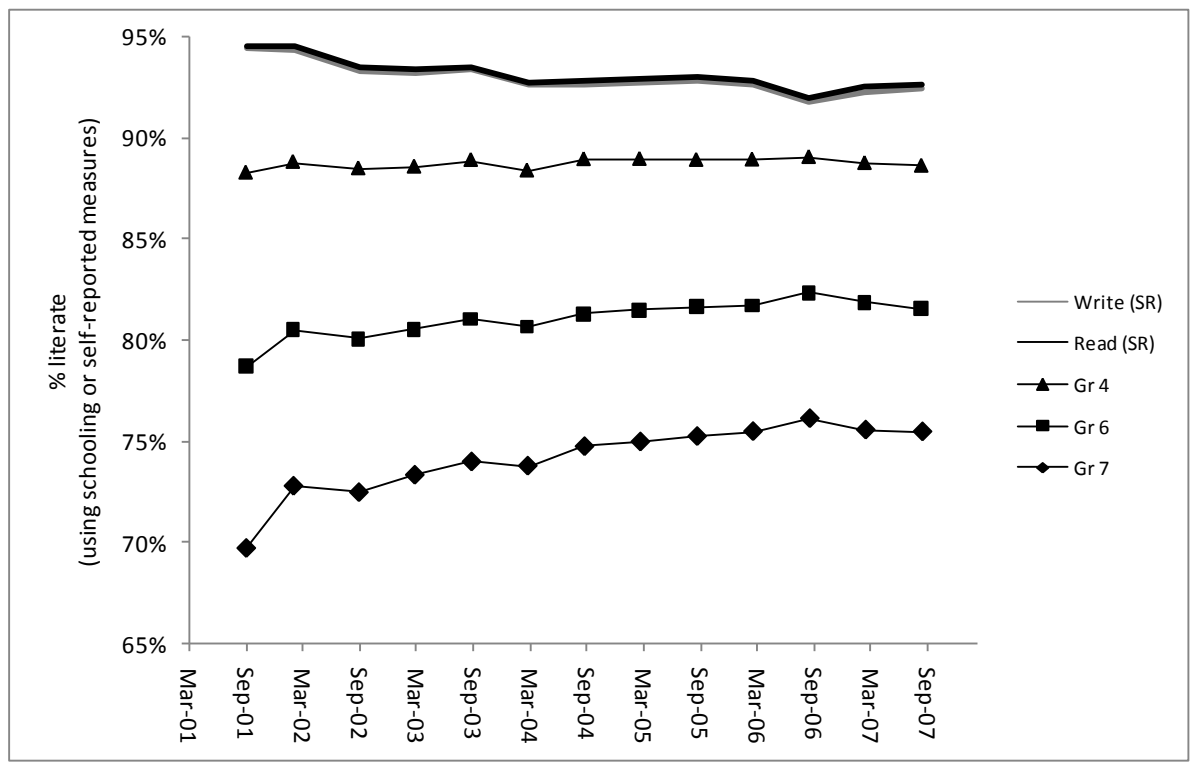

Source: Stats SA, 2007. Note: The 'Write (SR)' and 'Read (SR)' curves overlap almost perfectly, and are therefore not distinguishable. Individuals aged 15 to 50 considered in 2001, and thereafter these parameters increased by 1 in each new year.

The following graph illustrates the literacy trend by age. What this pattern implies is that even if there is no adult education intervention, there will be improvements to the literacy rate over time, simply because adults with less literacy are replaced by adults with more literacy over time. As an example, some simple modelling reveals that a literacy rate of $90 \%$ in 2007 (using the Grade 4 criterion) becomes $93 \%$ in $2015,96 \%$ in 2025 and $98 \%$ in 2050, just on the basis of the present educational profile of young adults.

Figure 4: Labour Force Survey literacy adult trend by age (2007)

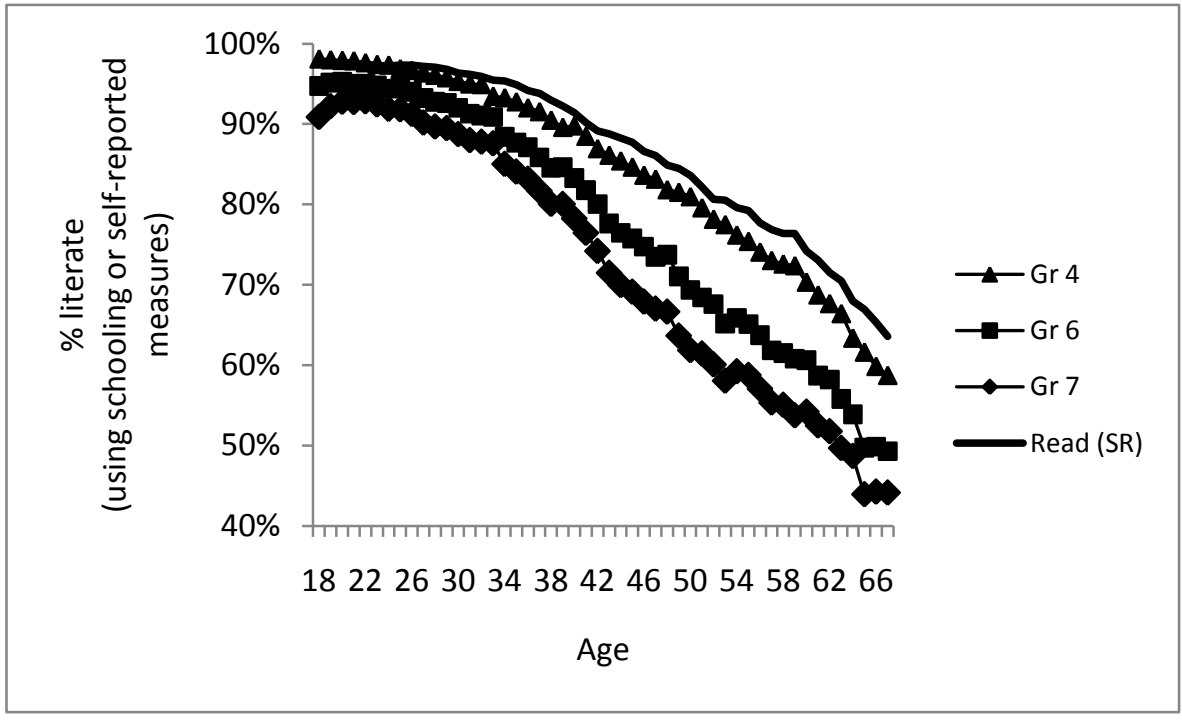

Source: Stats SA, 2007.

In the following graph, we explore the link between the self-reported literacy variable and the grade attainment variable. As one would expect, those adults with fewer years of schooling would regard themselves as less literate. But what is striking is that the relationship between highest grade attained and self-reported literacy appears to be changing over time. For example, in 2001, 98\% of adults aged 15 and over with a Grade 5 education considered 
themselves literate. In 2007 only $92 \%$ did. A very similar pattern emerges if we limit the analysis to adults aged 20 to 29 . What this suggests is that over time adults are becoming more stringent in their self-reporting of ability to read and write. The trend seems to have been particularly strong between 2001 and 2005. One can speculate that a more competitive and information-driven society is making people downgrade their own sense of being literate as they experience more barriers relating to their levels of literacy. This is what explains the downward trend in self-reported literacy in Figure 3 and Figure 4 above. These patterns confirm that subjective self-reported measures of literacy are highly unreliable. Not only are they likely to be incomparable across countries, they are moreover unstable within a country over time.

\section{Figure 5: Relationship between education and self-reported literacy}

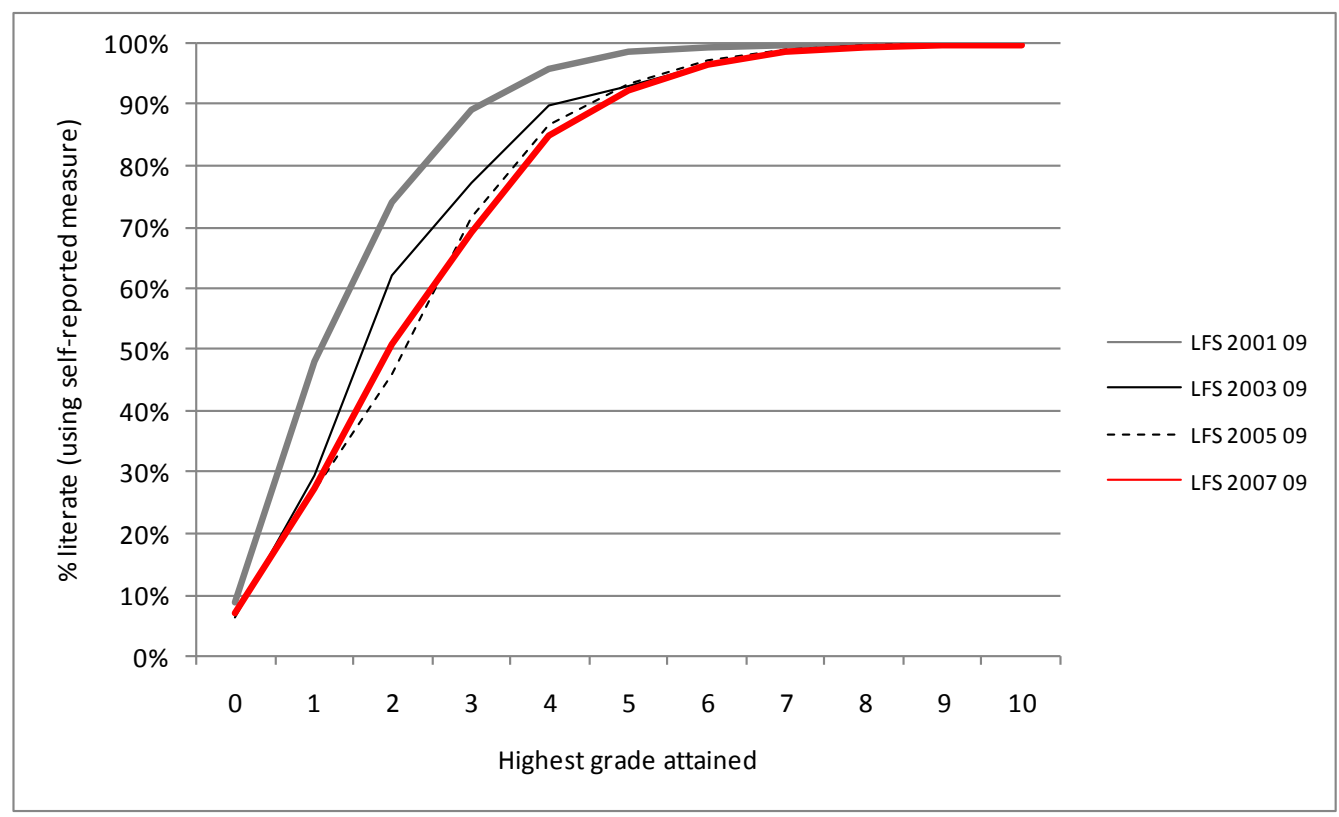

Source: Stats SA, 2007. Note: Reading variable used on vertical axis. The population aged 15 and above is considered.

One thing that should be noted about the above graph is that Grade 7 appears to be a relatively stable anchor in the sense that by this level of grade attainment, virtually all adults report being literate across all years. The self-reported literacy rate at the Grade 7 level is not less than $98.5 \%$ in any year. This would support the use of the Grade 7 threshold as a 'safe' one. An adult who has attained Grade 7 is very unlikely to feel illiterate, but substantial numbers of adults with less than Grade 7 are likely to feel illiterate, with the proportion increasing the lower the grade.

The next graph focuses on the relationship between self-reported literacy and completion of primary schooling across a small selection of middle income countries where UNESCO published self-reported literacy rates. South Africa's situation is by no means atypical. In all the countries in the graph, self-reported literacy is higher than the rate one would obtain using primary school completion, and the gap between the two measures is in fact lower in South Africa than in the other countries, whether one uses the data published by UNESCO (ZAF1) or 2007 Stats SA figures (ZAF2). But we could find no telling patterns in the relationship. Moreover, the gap or ratio between the two measures was not found to have any clear relationship with school quality measures such as those of PIRLS (PIRLS data are discussed in section 6). 


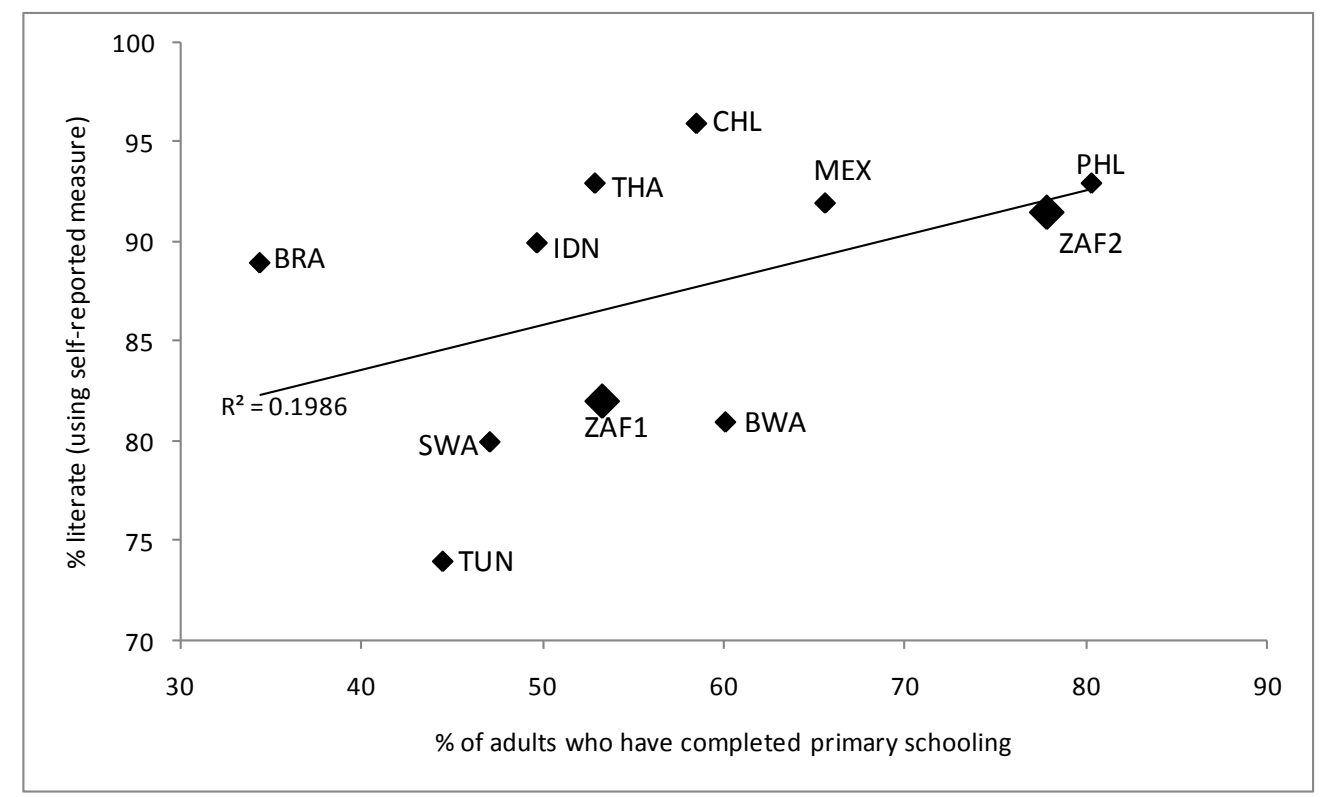

Source: UNESCO, 2007; Barro and Lee, 2001. Note: ZAF1 is derived from the same sources as the other countries, whilst ZAF2 is derived from Stats SA (2007).

The pattern we see in Figure 5 underlines an important point. One should not expect a reliable measure of literacy to display any drastic threshold points in a comparison against grade attainment. One should expect people to attain some benchmark level of literacy in different ways in the schooling system. Some will attain it in a lower grade than others, depending on such factors as innate ability, socio-economic background and the quality of the school. An important policy tool that would assist the targeting of adult literacy programmes is a profile such as the one in Figure 5, but with some standardised test-based scale along the vertical axis. The curves would probably be similarly shaped, but certainly lower in the graph, given that the self-reported literacy rate can be considered an over-estimate. This tool, which could be devised on the basis of a sample-based testing of adults that included grade attained as a background variable, could assist in planning where to target adult education programmes (the distribution of grade attainment across the country is relatively well known through various Stats SA sources).

Table 1 below provides literacy rates for the whole population of adults (aged 15 and above) and for sub-groups of this population. The first column gives the literacy rate using the LFS self-reported reading ability variable (which is virtually equal to the self-reported writing ability variable). In the second column, the Grade 6 attainment criterion is used. 
Table 1: LFS-based literacy rates by category in South Africa (2007)

\begin{tabular}{|c|c|c|c|}
\hline & $\begin{array}{c}\text { Self- } \\
\text { reported } \\
\text { literacy } \\
\text { (using } \\
\text { reading) }\end{array}$ & $\begin{array}{l}\text { Grade } 6 \\
\text { criterion }\end{array}$ & $\begin{array}{l}\text { Number not } \\
\text { literate } \\
\text { (using self- } \\
\text { reported) }\end{array}$ \\
\hline All & 90 & 78 & $3,354,775$ \\
\hline Men & 91 & 79 & $1,332,043$ \\
\hline Women & 88 & 77 & $2,022,732$ \\
\hline African & 88 & 74 & $3,121,003$ \\
\hline Coloured & 93 & 81 & 202,730 \\
\hline Indian & 99 & 93 & 12,777 \\
\hline White & 99 & 99 & 18,267 \\
\hline $\mathrm{EC}$ & 96 & 87 & 147,385 \\
\hline FS & 87 & 69 & 576,416 \\
\hline GP & 86 & 70 & 110,684 \\
\hline $\mathrm{KN}$ & 90 & 77 & 197,697 \\
\hline LP & 89 & 75 & 723,663 \\
\hline MP & 86 & 71 & 314,311 \\
\hline NC & 96 & 89 & 330,061 \\
\hline NW & 82 & 73 & 410,082 \\
\hline WC & 84 & 73 & 543,598 \\
\hline Afrikaans & 95 & 87 & 236,521 \\
\hline English & 99 & 97 & 19,332 \\
\hline IsiNdebele & 82 & 71 & 118,533 \\
\hline IsiXhosa & 88 & 71 & 656,177 \\
\hline IsiZulu & 88 & 74 & 912,412 \\
\hline Sepedi & 87 & 77 & 403,990 \\
\hline Sesotho & 90 & 76 & 244,604 \\
\hline Setswana & 87 & 75 & 333,624 \\
\hline SiSwati & 85 & 74 & 125,119 \\
\hline Tshivenda & 89 & 80 & 72,189 \\
\hline Xitsonga & 81 & 65 & 220,831 \\
\hline Age 15-24 & 98 & 90 & 229,666 \\
\hline Age 25-34 & 97 & 89 & 282,738 \\
\hline Age 35-44 & 92 & 79 & 431,262 \\
\hline Age $45-54$ & 84 & 64 & 652,369 \\
\hline Age $55-64$ & 74 & 53 & 802,956 \\
\hline
\end{tabular}

The patterns are mostly what one would expect. The patterns by gender and race reflect the country's history of discrimination. Moreover, the older the population, the greater the level of illiteracy. This one would also expect, given the improvements over recent decades in the grade attainment of adults ${ }^{21}$. The pattern with respect to home languages, however, seems to provide insight into historical factors that are often ignored. The literacy rates for the smaller languages appear to reflect a degree of marginalisation in the past. This is particularly true for IsiNdebele (spoken by around $2 \%$ of adults) and Xitsonga (spoken by around $4 \%$ of adults), regardless of which literacy rate one looks at. This pattern for these two languages is also evident if one controls for the other explanatory variables in a logistic regression (detailed results of this analysis are not provided here). It is possible that problems such as the unavailability of textbooks in the home language in the past would have affected schooling adversely for these language groups. This obviously has important implications for the targeting of adult literacy programmes today, and underlines the importance of having materials in all languages. The fact that Tshivenda (around 2\% of adults) and SiSwati (around $3 \%$ ) should not display similarly low literacy rates, despite being small languages, could have to do with counteracting historical factors such as the proximity of Swaziland (which could have assisted the availability of learning materials in SiSwati) and the fact that Venda became

\footnotetext{
${ }^{21}$ Department of Education, 2008.
} 
one of the nominally independent homelands under apartheid, a move that was rewarded with preferential public funding from the central apartheid government.

Up to this point, the focus has been on individual adults. Focussing on literacy patterns at the household level can be at least as important. Specifically, the percentage of households with at least one literate adult is an important indication of the access people have to someone who can assist them with matters such as enrolling in schools, applying for a social grant, applying for a job, and so on. The household-level statistics are in fact better than the individual levelones. Whilst $90 \%$ of adults describe themselves as literate, $96 \%$ of households have at least one adult who reports being literate. Similarly, whilst $82 \%$ of adults have at least Grade 6 , $92 \%$ of households have at least one adult with at least Grade 6.

Undoubtedly, having literacy statistics based on standardised testing of adults would be ideal for understanding the problem, and designing interventions. However, alternatives to the usual Stats SA datasets provide some insights into what one should look for in alternative measures of literacy, and what values one might expect. For instance, two of the national learner testing programmes from the last decade have included data collection from parents, with a special focus on the educational characteristics and behaviour of parents (though no literacy test was applied to the parents). These two programmes are the international PIRLS programme and the Department of Education's Systemic Evaluation. The next table extracts a few statistics from the PIRLS 2006 dataset. It is noteworthy that the correlation between grade attained and time spent reading amongst the learners of parents is rather low (around 13\% just using the four levels of reading shown in the table, and seven levels of education). More pertinent to the focus of this section of the report, $75 \%$ of parents report reading at least one hour per week. This statistic is arguably more telling than either the self-reported literacy or the grade attainment statistics discussed above. It is unlikely that someone who reports reading over one hour per week in a survey such as PIRLS is illiterate. The question, because it relates to an activity, as opposed to an assessment of one's own abilities, is probably less prone to subjectivity. The last column suggests that if one imposed a cut-off of at least one hour of reading a week, then the adult literacy rate would be $75 \%$. One could also impose more stringent requirements, and arrive at lower literacy rates, such as $31 \%$ if one's requirement is at least six hours of reading a week. How representative would the PIRLS respondents be of South Africa's adults? It is difficult to tell, but of relevance here is the fact that more women than men provided responses (9,336 female respondents, against 5,209 male respondents, but with a large number of respondents, 3,009, with the gender variable left blank). Any parent or guardian in the home was permitted to fill in the questionnaire, and only one questionnaire was sent to each learner's household. The fact that there are adults in households who are not parents of learners in Grade 5 (the grade tested in PIRLS 2006) would clearly diminish the credibility of generalising on the basis of the Table 2 statistics. Nevertheless, given the general paucity of good data on adult literacy, a statistic such as the $75 \%$ 'literacy rate' seen in the table provides us with a rough indication of the minimum level of literacy amongst adults. Adults who read less than one hour a week could of course also be literate, which is why the $75 \%$ is best viewed as a minimum. But would an adult who hardly ever reads, in a society where newspapers are fairly widespread, really qualify as being literate? These are questions that need to inform improvements in our monitoring of adult literacy. 
Table 2: An alternative view on literacy (I)

\begin{tabular}{|c|c|c|c|c|c|c|}
\hline & $\begin{array}{l}\text { Not Gr } \\
\quad 9\end{array}$ & Gr 9 & Gr 12 & $\begin{array}{l}\text { Post- } \\
\text { Gr } 12\end{array}$ & Total & $\begin{array}{c}\text { Cumulative } \\
\text { ('literacy } \\
\text { rate') }\end{array}$ \\
\hline \multicolumn{7}{|c|}{$\begin{array}{l}\text { Time spent reading to oneself (including books, magazines, newspapers and materials for } \\
\text { work) in a typical week: }\end{array}$} \\
\hline$<1$ hour/week & 6 & 6 & 9 & 4 & 25 & 100 \\
\hline 1-5 hours/week & 6 & 7 & 21 & 9 & 44 & 75 \\
\hline 6-10 hours/week & 3 & 3 & 6 & 5 & 17 & 31 \\
\hline >10 hours/week & 2 & 3 & 5 & 4 & 14 & 14 \\
\hline Total & 17 & 19 & 41 & 23 & 100 & \\
\hline
\end{tabular}

Hanushek and Woessman (2007: 57) argue that the adult literacy rate in South Africa is only $7 \%$, using an extremely stringent approach where they combine enrolment data and internationally comparable learner test scores. To compare, Brazil's adult literacy rate, using the same methodology, is found to be only 8\%. Colombia and Egypt, on the other hand, enjoy literacy rates of $30 \%$ and $32 \%$. Clearly, if one considers the low level of learner achievement in schools, then adult literacy rates of over $80 \%$ for South Africa appear to be incongruously high. In PIRLS 2006, only 22\% of Grade 5 learner reached the 'low international benchmark' of 400 points, meaning only $22 \%$ of learners were able to read and write, using the lowest standard contemplated within the PIRLS programme (there are several international benchmarks within PIRLS, and if one were to use a higher one the $22 \%$ 'literacy rate' for South Africa would obviously be even lower). This $22 \%$ should be compared to the fact that $92 \%$ of adults with Grade 5 considered themselves literate in 2007 (see Figure 5). Even the more realistic comparison between a $22 \%$ 'literacy rate' for Grade 5 learners and the fact that $65 \%$ of PIRLS parents with less than Grade 9 read for more than an hour a week, still points to an incongruity (the PIRLS parent questionnaire pools everything from no schooling to not completing lower secondary schooling into one categorical value, so it is not possible to isolate, for instance, Grade 5). It seems very unlikely that this discrepancy, a discrepancy found in many developing countries, could be the result of (or mainly the result of) a deterioration in the quality of schooling (meaning older adults with just Grade 5 would be more literate than learners in Grade 5). It seems much more plausible to ascribe the discrepancy to measurement problems and, perhaps, to the fact that literacy skills are accumulated by adults beyond formal schooling, in an informal manner (such as through the reading of newspapers).

To conclude this section, the available data do not allow us to determine with reasonable certainty what percentage of adults are able, for instance, to read a paragraph (the Stats SA criterion for adult literacy). It is probably safe to assume, however, that the adult literacy rate is at least $75 \%$, based on who reads at least an hour a week, according to the PIRLS (admittedly problematic) sample of parents we have. How much higher than $75 \%$ the actual figure is, is debatable. It seems unlikely that it is as high as $88 \%$, the level calculated and published by UNESCO. The only way of obtaining such a high figure is to use self-reported literacy, which we have seen is unstable (even for the same people over time), or a very low grade attainment assumption (in fact even lower than Grade 4, judging from Figure 2). The Grade 6 attainment criterion, which gives a rate of $78 \%$ in 2007, seems more credible. The Grade 7 criterion, which gives $71 \%$, is perhaps too stringent, though it is safe in the sense that one is unlikely to exclude many adults who feel they are illiterate. But grade attainment is a far from ideal measure of adult literacy, as suggested by poor results in standardised testing programmes in the schools, such as PIRLS. There is no good reason for not measuring adult literacy directly, using for instance the sample-based and test-based methodology of UNESCO's LAMP programme. Such a method can provide reliable results at a relatively low cost. 


\section{The individual effects of illiteracy}

Here two key impacts of adult literacy (and, by implication, possession of a basic education amongst adults) are explored: the impact on the performance of children in school, and the impact on being employed.

The Progress in International Reading Literacy Study (PIRLS) of 2006 provides us with an opportunity to examine linkages between parent (including parent literacy) factors and learner performance. In South Africa, PIRLS 2006 tested a representative sample of around 14,000 Grade 5 learners, and collected contextual information from the learners themselves, their schools, their teachers and their parents through questionnaires. The reading scores are set on a scale with an average of 500 and a standard deviation of 100 across all countries. Table 3 below provides the results of an education production function (also sometimes referred to as an education input-output model), linking 21 input variables with the reading scores of the South African learners. The statistical model is a weighted clustered survey regression model $^{22}$. Two of the input variables, the socio-economic status (SES) of learners and the school infrastructure index, are compound indices constructed from several variables in the dataset, using a principal components approach. In line with common practice, missing learner-level values were imputed using the school-level mode, whilst missing school-level values resulted in the omission of whole schools from the analysis. Model A below is for the entire South Africa PIRLS sample, whilst model B uses only those schools where testing occurred in one of the nine African languages (in other words not in English or Afrikaans). Model B allows us to focus on the dynamics of historically disadvantaged school communities, where the need for quality improvements is most urgent ${ }^{23}$. It should be noted that a substantial number of learners from homes where an African language is spoken would be excluded from model B. These African learners, who would mostly have written the test in English, would generally be middle class learners attending schools which may or may not be historically African. This largely explains why around $31 \%$ of learners are not included in model B below, whilst only $17 \%$ of children aged 5 to 14 do not speak an African language at home (according to the 2007 LFS).

\footnotetext{
${ }^{22} \mathrm{~A}$ separate report which is an appendix to this paper provides full details on the analysis summarised here.

${ }^{23}$ See for instance Van der Berg (2007) for an account of the race dimensions of the educational quality issues in South Africa.
} 
Table 3: School production function results

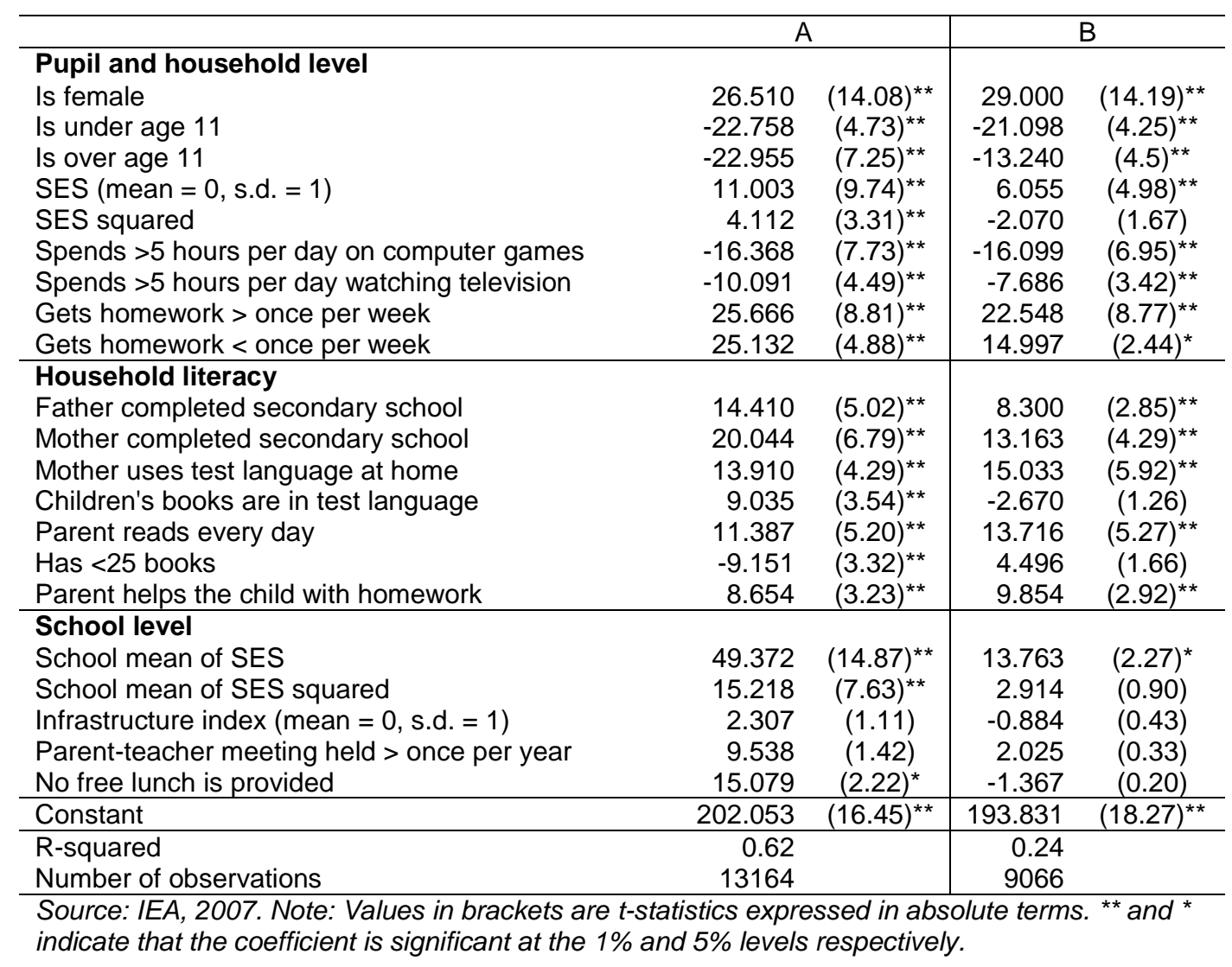

Parent education makes a difference to learner performance. Specifically, in historically African schools, if both the mother and the father had completed secondary schooling, the expected PIRLS score of the learner would be about 21 points higher ( 8.300 plus 13.163 , and almost a quarter of one standard deviation on the cross-country scale), compared to learners whose parents had both not completed secondary schooling. The fact that the association with the mother's education should be greater than that with the father's education underlines the importance of educating females for human capital transfer across generations. And the fact that the effects of parent education in historically African schools should be lower than those in the full sample could point to problems these schools experience in translating home background advantage to outstanding classroom performance, a phenomenon that has been examined by, for instance, Van der Berg (2008). Of more direct relevance to the question of the impact of basic literacy, parents who say that they read every day are associated with an improvement of 14 PIRLS points in the African language sub-sample.

The two book variables, namely having less than 25 books in the home and having children's books that are in the PIRLS test language, yield no meaningful or statistically significant coefficients in the model. This is surprising, given positive evidence on the impact of books or newspapers in the household in other analyse ${ }^{24}$. This should serve as a reminder that these kinds of production function results are sensitive to a range of data and modelling problems, and that firm policy conclusions should only be drawn from the accumulation of knowledge across several such models.

\footnotetext{
${ }^{24}$ See for instance Hanushek and Luque (2003: 490). Gustafsson and Patel (2008: 33) find, using the South Africa's 2004 Systemic Evaluation dataset, that having newspapers in the home is associated with better reading and mathematics scores.
} 
Further variables in the model relating to parent behaviour (and potentially subject to influence through adult education) include helping the child with homework (improvement of 10 PIRLS points in the African language sub-sample), and allowing children to watch more than five hours of television or play computer games for more than five hours per week (both display substantial negative associations with learner performance, and the data indicate that the percentage of African learners surpassing the five hour threshold is $20 \%$ for both activities).

To put the parent variables in context, if we add the parent education and parent behaviour effects in the African language sub-sample, we obtain around 85 PIRLS points. This provides a sense of the difference that parents can make, if one's improvement occurs off a low base. We can compare this to a 2 point improvement associated with more parent-teacher meetings, a 1.3 point improvement if free lunches are provided at the school, or an 8 point improvement if the SES value shifts by one standard deviation from -1.0 to 0.0 . The model undoubtedly supports a strong policy focus on parent education and behaviour.

Next, we examine the impact of a basic education and adult literacy on being employed. We decided to limit our focus to employment as a dependent variable here, as opposed to wage, given the high unemployment rate in South Africa (officially 22\% in 2008), and the strong emphasis on tackling unemployment in government and non-government circles.

The following table presents the result of a logit regression model in which whether someone is employed or not is regressed on the ten explanatory variables. The analysis is limited to non-students aged 18 to 35 , an age range in which unemployment is especially high. Of the individuals analysed by the model, $57 \%$ are not employed, and the official unemployment figure would be $38 \%$. All ten variables are significant at the $1 \%$ level.

Table 4: Employment model results

\begin{tabular}{|c|c|c|c|c|c|c|}
\hline \multicolumn{3}{|c|}{ Regression results } & \multicolumn{4}{|c|}{ Simulation } \\
\hline $\begin{array}{l}\mathrm{N} \\
\text { Pseudo R-squared }\end{array}$ & & $\begin{array}{c}23952 \\
0.14\end{array}$ & & & & \\
\hline & $\begin{array}{l}\text { Coeff- } \\
\text { icient }\end{array}$ & $z$ & $\begin{array}{c}\text { Med- } \\
\text { ian } \\
\text { value }\end{array}$ & $\begin{array}{l}\text { Assumed } \\
\text { value } \\
\text { after shift }\end{array}$ & $\begin{array}{c}\text { New prob- } \\
\text { ability } \\
\text { (base }=0.54 \text { ) }\end{array}$ & $\begin{array}{c}\text { Change } \\
\text { (percent- } \\
\text { tage points) }\end{array}$ \\
\hline Years of schooling & 0.038 & 3.08 & 11 & 12 & 0.58 & 0.9 \\
\hline Has Grade 12 & 0.436 & 7.31 & 0 & 1 & 0.68 & 10.2 \\
\hline Reports ability to read & 0.359 & 2.82 & 1 & 0 & 0.49 & -8.9 \\
\hline Age & 0.385 & 7.23 & 27 & 28 & 0.60 & 2.6 \\
\hline Age squared & -0.005 & -5.16 & & & & \\
\hline Is female & -0.979 & -23.06 & 1 & 0 & 0.78 & 20.8 \\
\hline Speaks African language & -0.979 & -17.18 & 1 & 0 & 0.78 & 20.8 \\
\hline Max. schooling in household & -0.108 & -18.02 & 10 & 11 & 0.55 & -2.7 \\
\hline Other in household is employed & 0.406 & 8.74 & 1 & 0 & 0.47 & -10.1 \\
\hline Lives in metro & 0.345 & 6.96 & 0 & 1 & 0.66 & 8.1 \\
\hline Constant & -5.865 & -8.22 & & & & \\
\hline
\end{tabular}

The simulation in the right-hand panel in Table 4 can be explained as follows:

- Having Grade 12, as opposed to Grade 11, improves one's probability of being employed by 11 percentage points (10.2 plus 0.9$)$. Other grade attainment increases, for instance from Grade 10 to Grade 11, are associated with only with very small improvements in one's probability of being employed, equal to 0.9 percentage points per grade. This prominence of Grade 12 can be linked to the importance of the Matric qualification as a 
provider of labour market signals, and the absence of similar qualifications at other levels of the schooling system.

- Self-reported ability to read is associated with an 8.9 percentage point improvement in one's probability of being employed. Although only $4 \%$ of the adults analysed by the model describe themselves as being unable to read, the fact that self-reported literacy should have a statistically significant association with employment, whilst controlling for years of schooling, seems important ${ }^{25}$. It suggests that apart from highest grade attained, people's perceptions of their own ability to read is a relevant criterion when targeting adult education programmes at potential students. In other words, providers can use grade attainment cut-offs when recruiting students, but they should also encourage anyone who perceives himself as illiterate, regardless of highest grade attained, to enrol.

- The reduction in one's probability of being employed associated with being female and African is high (and virtually the same for the two explanatory variables). Apart from labour market discrimination and problems in accessing employment-inducing social networks, a problem linked to the being African variable is that the quality of schooling in historically African schools has tended to be poor.

- Household factors such as the years of schooling of the most educated other household member, and whether anyone in the household is employed, are significant, underlining the importance of targeting adult education towards areas where a high proportion of households (as opposed to individuals) experience human capital and employment deprivation.

- Finally, living in one of the six metropolitan areas in the country is associated with an increase in one's employment probability of 8 percentage points, underlining the importance of targeting rural areas in employment interventions.

It is should be noted that neither the employment model, nor the school model in this section are able to establish the direction of causality between variables, for instance, between selfreported literacy and one's probability of being employed. It is frequently possible that the causality is complex, and that it works in both directions. For instance, literacy may indeed be a reason contributing towards better employment prospects. However, it is possible that some of the association relates to the fact that employment causes better literacy (and confidence in one's ability to read) through work experience. But the room for interpretation depends on the relationship being considered. It is unlikely that learner literacy would cause parent literacy in any significant manner, for instance, so in this instance there could be greater certainty about the effect (namely that parent literacy assists learner literacy).

\footnotetext{
${ }^{25}$ A variable on whether one had completed primary schooling was added to the model, and was found to be statistically insignificant.
} 


\section{The social and economic costs of illiteracy to the country}

The economic modelling presented in this section is aimed at quantifying the cost of illiteracy, in terms of country-level aggregate income (and hence, in monetary terms). But before we turn to this modelling, the World Values Survey dataset provides an opportunity to examine linkages between literacy and social benefits, such as social cohesion, which are difficult to evaluate in monetary terms.

The World Values Survey last collected information from South Africa in 2005, when a sample of around 3,000 adults aged 16 and above were interviewed. According to that dataset, $80 \%$ of respondents had completed primary schooling, and $49 \%$ had read a newspaper in the last week - these criteria form the basis for defining literacy in Table 5 below.

People's values are a function of many different variables. What is presented in Table 5 are simple descriptive statistics, and not an attempt to disentangle the multivariate relationships (the dataset does lend itself towards such analysis, however). Race, age and gender would undoubtedly influence people's values in the South African context, so it is important to read the table in the light of this breakdown. We see, for instance, that Africans make up the great majority of both illiterate and literate respondents (however one defines literacy). This group would thus predominate in the statistics for all four columns in the table. The gender breakdown is relatively even. The literate (especially if one uses the primary school criterion) would tend to be younger than the non-literate.

The percentages in Table 5 from 'Health' to 'Non-violent' indicate the percentage of respondents displaying the desirable characteristic. Thus, $85 \%$ of respondents are considered to be non-violent as around $85 \%$ of them indicated that it was not acceptable for a man to beat his wife. If we begin with the factors that are important for social cohesion, we see considerably greater interest in politics amongst the literate (whichever way we define literacy) and perhaps a greater interest in democracy, though for both groups more than $90 \%$ of respondents support democracy. (Differences such as that between $93 \%$ and $94 \%$ are so small that, given the size of the sample, it is possible that there is no difference. We need a difference of around two percentage points before we can be about $95 \%$ certain there is indeed a difference). Completing primary school seems to be associated with less sexism, but regular reading of newspapers does not seem to have the same effect. Acceptance of genderbased violence (almost 13\% of respondents, and 15\% of male respondents, believe it is justifiable to beat one's wife) does not seem to be lower amongst the more literate. Over half of respondents trust three key institutions of the state, the government, the police and the courts, but a substantial minority do not, and that minority is larger amongst the literate. This is to be expected, and the pattern is similar in many other countries. Fewer than half of respondents trusted political parties (in 2005), and the distrust was substantially larger amongst the literate. This lack of trust can of course be desirable insofar as it translates into political pressure for institutions to improve. On a personal level, people who are literate tend to feel healthier, more satisfied with life, and less used by others. The association between completing primary schooling and self-reported health is particularly strong. 
Table 5: Literacy and values

\begin{tabular}{|c|c|c|c|c|c|}
\hline \multirow[b]{2}{*}{ Characteristic } & \multirow[b]{2}{*}{ Question } & \multicolumn{2}{|c|}{$\begin{array}{l}\text { Criterion: Completed } \\
\text { primary school }\end{array}$} & \multicolumn{2}{|c|}{$\begin{array}{l}\text { Criterion: Reads } \\
\text { newspapers }\end{array}$} \\
\hline & & $\begin{array}{l}\text { \% for } \\
\text { illiterate }\end{array}$ & $\begin{array}{l}\text { \% for } \\
\text { literate }\end{array}$ & $\begin{array}{l}\text { \% for } \\
\text { illiterate }\end{array}$ & $\begin{array}{l}\text { \% for } \\
\text { literate }\end{array}$ \\
\hline $\begin{array}{l}\% \text { of all } \\
\text { respondents }\end{array}$ & & 20 & 80 & 51 & 49 \\
\hline $\begin{array}{l}\text { Completed } \\
\text { primary school }\end{array}$ & $\begin{array}{l}\text { What is the highest educational level } \\
\text { that you have attained? }\end{array}$ & 0 & 100 & 67 & 93 \\
\hline $\begin{array}{l}\text { Reads } \\
\text { newspapers }\end{array}$ & $\begin{array}{l}\text { Did you read a daily newspaper last } \\
\text { week? }\end{array}$ & 17 & 57 & 0 & 100 \\
\hline \multirow{4}{*}{$\begin{array}{l}\text { Age } \\
\text { Is female } \\
\text { Speaks Afrikaans } \\
\text { Speaks African } \\
\text { language }\end{array}$} & & 50 & 34 & 38 & 36 \\
\hline & & 48 & 51 & 56 & 44 \\
\hline & & 1 & 12 & 5 & 15 \\
\hline & & 95 & 74 & 88 & 69 \\
\hline \multirow{2}{*}{$\begin{array}{l}\text { Health } \\
\text { Not used }\end{array}$} & How would you describe your health? & 55 & 84 & 72 & 85 \\
\hline & $\begin{array}{l}\text { Do you think people take advantage } \\
\text { of you? }\end{array}$ & 52 & 57 & 52 & 60 \\
\hline \multirow{4}{*}{$\begin{array}{l}\text { Satisfied } \\
\text { Work ethic } \\
\text { Political } \\
\text { Democratic }\end{array}$} & How satisfied are you with your life? & 66 & 77 & 70 & 80 \\
\hline & Is work a duty towards society? & 73 & 75 & 72 & 77 \\
\hline & Are you interested in politics? & 38 & 46 & 41 & 48 \\
\hline & $\begin{array}{l}\text { Is it good to have a democratic } \\
\text { system? }\end{array}$ & 91 & 94 & 93 & 94 \\
\hline $\begin{array}{l}\text { Experiences } \\
\text { democracy }\end{array}$ & How democratic is your country? & 85 & 82 & 84 & 81 \\
\hline Trusts police & $\begin{array}{l}\text { Do you have confidence in the } \\
\text { police? }\end{array}$ & 67 & 61 & 66 & 58 \\
\hline Trusts courts & $\begin{array}{l}\text { Do you have confidence in the } \\
\text { courts? }\end{array}$ & 75 & 64 & 71 & 62 \\
\hline $\begin{array}{l}\text { Trusts } \\
\text { government }\end{array}$ & $\begin{array}{l}\text { Do you have confidence in the } \\
\text { government? }\end{array}$ & 80 & 68 & 75 & 66 \\
\hline Trusts parties & $\begin{array}{l}\text { Do you have confidence in the } \\
\text { political parties? }\end{array}$ & 50 & 42 & 47 & 41 \\
\hline Pays taxes & Is it justifiable to cheat on taxes? & 85 & 88 & 88 & 87 \\
\hline Social cohesion & $\begin{array}{l}\text { Do you trust people in your } \\
\text { neighbourhood? }\end{array}$ & 77 & 72 & 74 & 71 \\
\hline Non-sexism & $\begin{array}{l}\text { Do you believe that men make better } \\
\text { political leaders? }\end{array}$ & 41 & 51 & 49 & 50 \\
\hline Non-xenophobic & $\begin{array}{l}\text { Should employers give preference to } \\
\text { South Africans? }\end{array}$ & 26 & 21 & 21 & 23 \\
\hline Non-violent & $\begin{array}{l}\text { Is it justifiable for a man to beat his } \\
\text { wife? }\end{array}$ & 85 & 88 & 88 & 86 \\
\hline
\end{tabular}

Source: World Values Survey Association, 2008. Note: In the rows referring to people's values, the percentage shown is the percentage of respondents displaying the desirable characteristic, for instance responding that it is not justifiable for a man to beat his wife. In cases where in the data there was a scale for the response (for instance agreement on a scale of 1 to 10), the binary response needed for the above statistics was imputed based on what seemed reasonable (for instance 1 to 5 meaning disagreement and 6 to 10 meaning agreement).

Overall, the link between literacy and desirable values in society is perhaps not as strong as one may have thought. In particular, it is telling, and probably counter-intuitive, that literacy should not appear more strongly associated with less sexism, and a greater intolerance of violence. The problem could lie in the simplicity of the analysis provided by the above table (the aim here is merely to provide a glance at the World Values Survey, not an in-depth analysis of the data). But the patterns we see could also serve as a useful reminder that schooling and newspapers per se are not a guarantee of more desirable social values. Schooling and newspapers can serve as vehicles for the dissemination of such values, if they convey the necessary messages in an effective manner. 
We now turn to the core concern of this section, determining the monetary cost of illiteracy. Here we make use of cross-country growth models that include a human capital element. These models have existed for several decades and have increasingly moved from more tangible explainers of economic growth, such as fertility and investment in physical capital, to more intangible explanatory variables, such as the level of human capital and the country's ability to harness recent technologies, or even create new technologies. GDP per capita, or year-on-year growth in GDP per capita, in real inflation-adjusted terms, tends to be the variable being explained in these models. The assumption, often not made explicit, is that GDP per capita (or average income per capita) is important partly because it is a reliable indicator of the overall-well being of the citizens of a country, and the country's level of development. This assumption is clearly debatable, and alternative indicators have been devised, the best known probably being the Human Development Index of the UNDP. Here we do not enter these debates, and limit our attention to economic growth, which, despite certain limitations, is undoubtedly important for a country's development (and has been a cornerstone of both the RDP and ASGISA in South Africa).

The model we use is the 'augmented Solow model' of Mankiw, Romer and Weil (1992), who take one of the earliest growth models, that of Solow (1956), and augment it with a human capital element (something Solow had excluded from his model). In most economic growth models that include a human capital element, this element appears in the form of just one variable, for instance average years of education completed of adults, or the percentage of adults who have completed primary school. Here we adopt the less common approach of using two variables, one for a lower level of educational attainment (such as achieving basic literacy), and one for a high level of educational attainment (such as excelling at the tertiary level). There are good reasons for believing that one needs to focus separately on two different educational factors, especially when, as in this study, our concern lies in isolating the impact of being literate.

A key recent paper on the links between education and economic growth is that of Hanushek and Woessman (2007). This excellent paper (and a few others like it) can be regarded as seminal for education planners, as it explains rather convincingly how important improving the quality of schooling is for the development of countries, and how earlier analytical and policy emphases on years of schooling have to some degree been misplaced. Whilst enrolment-focussed programmes (such as UNESCO's Education for All at the global level) are undoubtedly valuable, allowing the inter-related issues of enrolments, grade attainment and dropping out to cloud the importance of reaching critical minimum levels of quality in schooling, raises the risk of inefficient public spending, and below optimal economic and social development. The need to re-focus on quality has been widely recognised. It receives in-depth attention in the 2005 Global Monitoring Report of the Education for All programme. In South Africa, improving educational quality in schools has assumed a new urgency in the Minister of Education's budget speeches, starting from around 2004.

Much of the analysis we perform here is similar to that of Hanushek and Woessman (2007). We use data on educational quality in the model, taking advantage of recent datasets from programmes applying standardised reading tests across several countries. Apart from TIMSS and PISA (used by Hanushek and Woessman), we use PIRLS 2006 and SACMEQ 2000 data. The latter dataset is of particular value not only because it includes South Africa and her regional neighbours, but also because it assists in introducing a critical mass of developing countries into the analysis. Here we elaborate on Hanushek and Woessman's (2007) methods of illustrating graphically how improving educational quality can impact on economic growth, and pay special attention to the policy implications for South Africa ${ }^{26}$.

\footnotetext{
${ }^{26}$ Subsequent to their 2007 paper, Hanushek and Woessman published a paper in 2009 which formalised their key 2007 arguments, and provided an analysis using both a low-level human capital
} 
The variables used in the modelling are listed in Table 6. The first three (income per capita, investment over GDP and the annual increase in the working age population) form the basis for the original Solow model. When Mankiw, Romer and Weil (1992) augmented the Solow model, what they did was introduce the secondary school enrolment level as a human capital variable (this is our fourth variable). We included two tertiary enrolment variables in our analysis to deal with high-level human capital: tertiary students per 1,000 inhabitants and engineering students at the tertiary level per 1,000 inhabitants. These two variables were not included in our final models as their performance as explanatory variables in the exploratory analysis was inconsistent. They are not unimportant variables, clearly, and they deserve serious attention in this kind of analysis. In particular, it was telling that the engineering variable appeared more significant than the general tertiary enrolment variable in some of the exploratory analysis (the details of which are not included in this report).

The two PIRLS variables listed in Table 6 were used as the most robust indicators of literacy in our final models. Of the 84 countries for which we obtained values, only 38 had actual PIRLS values (the PIRLS values we used were those for the 2006 run of the programme). PIRLS, or the Progress in International Reading Literacy Study, tested Grade 4 learners in reading and literacy, using standardised tests. South Africa, one of the few developing country participants, tested Grade 5 learners, instead of Grade 4 learners, and tests were conducted in the eleven official languages ${ }^{27}$. In the case of 46 countries for which PIRLS 2006 data were not available, PIRLS-like scores were assigned to students based on performance in four other international testing programmes, namely PISA ${ }^{28} 2000$ (reading score of 15 year olds used), PISA 2003 (reading score of 15 year olds used), SACMEQ ${ }^{29} 2000$ (Grade 6 reading score used) and TIMSS 2003 (Grade 8 mathematics score used). This was required largely to generate enough data for developing countries. The data processing is explained in Appendix A, and the values arrived at are given in Appendix B. The reason why TIMSS 2003 mathematics scores were used, despite the focus being on literacy, is partly that TIMSS served as a necessary vehicle for linking SACMEQ 2000 to PIRLS 2006, and partly that this allowed for the inclusion of even more developing countries, though wherever possible literacy scores, and not TIMSS mathematics scores, were used. Mathematics and language scores tend to correlate well with each other ${ }^{31}$, which seems to justify the use of the TIMSS score as a proxy for a literacy score.

\footnotetext{
variable, and a high-level one, using low and high thresholds within the learner performance data. This is partly similar to what is done in this paper to cater for levels of human capital.

${ }^{27}$ Mullis, Martin, Kennedy and Foy, 2007: 30, 133.

${ }^{28}$ Programme for International Student Assessment, run by the OECD.

${ }^{29}$ Southern and Eastern African Consortium for Measuring Educational Quality, run by the International Institute for Education Planning (IIEP) of UNESCO.

${ }^{30}$ Trends in International Mathematics and Science Study, run by the International Association for the Evaluation of Educational Achievement (IEA).

${ }^{31}$ The national averages for TIMSS 2003 mathematics and for PIRLS 2006 reading, for the 25 countries that participated in both, was 0.88 .
} 
Table 6: Variables used for the growth models

\begin{tabular}{|l|c|l|}
\hline Variable & Countries & Source \\
\hline $\begin{array}{l}\text { GDP per capita (in real PPP USD of 2006), average } \\
\text { 1990-2003 }\end{array}$ & 163 & Heston, Summers, and Aten, 2006. \\
\hline $\begin{array}{l}\text { Gross capital formation (public and private) over } \\
\text { GDP, average 1990-2003 }\end{array}$ & 214 & UN Statistics Division, 2009. \\
\hline $\begin{array}{l}\text { Annual increase in working age population (age 15 } \\
\text { to 64), average 1990-2003 }\end{array}$ & 167 & UN Population Division, 2009. \\
\hline $\begin{array}{l}\text { Gross enrolment ratio in secondary schooling, } \\
\text { average 1990-2003 }\end{array}$ & 202 & UNESCO: UIS, 2009. \\
\hline $\begin{array}{l}\text { Tertiary students per 1,000 inhabitants, average } \\
\text { 1990-2003 }\end{array}$ & 157 & UNESCO: UIS, 2009. \\
\hline $\begin{array}{l}\text { Engineering students (tertiary) per 1,000 inhabitants, } \\
\text { average 1990-2003 }\end{array}$ & 95 & UNESCO: UIS, 2009. \\
\hline $\begin{array}{l}\text { PIRLS 2006 mean score (could be imputed from } \\
\text { non-PIRLS dataset) }\end{array}$ & 84 & $\begin{array}{l}\text { IEA, 2007; IEA, 2004; IIEP: } \\
\text { SACMEQ, 2004; OECD, 2001; } \\
\text { OECD, 2004. }\end{array}$ \\
\hline $\begin{array}{l}\text { Percentage of learners achieving at least the PIRLS } \\
\text { 2006 low international benchmark (score of 400) }\end{array}$ & 84 & As above. \\
\hline $\begin{array}{l}\text { Springer journal articles published per 1,000 } \\
\text { inhabitants }\end{array}$ & 84 & Springer, 2009. \\
\hline Adult literacy ratio, average 1990-2003 & 136 & UNESCO: UIS, 2009. \\
\hline
\end{tabular}

Because we explicitly wanted to examine the effect of not reaching particular literacy thresholds, we used not just a variable on the average PIRLS 2006 score, but also a variable on the percentage of learners achieving the 'low international benchmark' score of 400 in PIRLS 2006 (where actual PIRLS data were not available, the imputed scores were used).

In an attempt to devise a variable that would capture the quality of high-level human capital (and not just something purely quantitative, such as tertiary enrolments), the number of articles ever published by authors, per country, in the journals currently owned by Springer Science+Business Media was used. Springer is the world's second-largest publisher of journals. The explanatory power of this variable turned out to be considerable. Only values from the 84 countries with PIRLS (or PIRLS-like) scores were used.

As far as possible, averages for the 1990-2003 period were used for the analysis. Data constraints made it impossible to apply this rule to the three quality variables (the two PIRLS variables, and the Springer variable). It is natural to ask whether one can meaningfully link learner quality data to contemporaneous GDP per capita data in a model (in fact, some of our learner quality data is more recent than the GDP per capita data). Should one not link learner data from an earlier generation, given that it takes many years for learners to reach the labour market, where they are able to use their acquired human capital to generate income? Growth models with a human capital element in fact tend to use contemporaneous school and income (or growth) data. Though this is not often explained, the justification is the assumption that improving schooling (whether one views schooling in quantitative or qualitative terms) is a slow process, so the current state of schooling is roughly similar to the state of schooling that the current labour force experienced in the past. It seems worth interrogating this assumption briefly, in particular given relatively new data that could shed some light on this matter.

The SACMEQ 2000 dataset is extraordinary insofar as it includes scores achieved by teachers in teacher tests designed to correspond to some degree with the learner tests. This is a feature not shared by most other international testing programmes. If learner scores are highly correlated with teacher scores at the country level, then this would provide support for the notion that education is to a large degree a transfer of knowledge and skills from teachers to learners, and that the educational limitations of teachers will to a large degree be replicated in 
education limitations amongst learners. This dynamic would, in turn, suggest that improving schooling is a very slow process involving a gradual growth in human capital over generations. Figure 7 below indicates that there is indeed a pattern (indicated by the $R^{2}$ value of 0.35 based on an exponential trendline), but that deviation from the pattern is not that difficult. To illustrate, Tanzania's teachers are amongst the least knowledgeable in the region (according to their scores), and yet their learners score amongst the highest in the region.

Figure 7: Learner and teacher performance

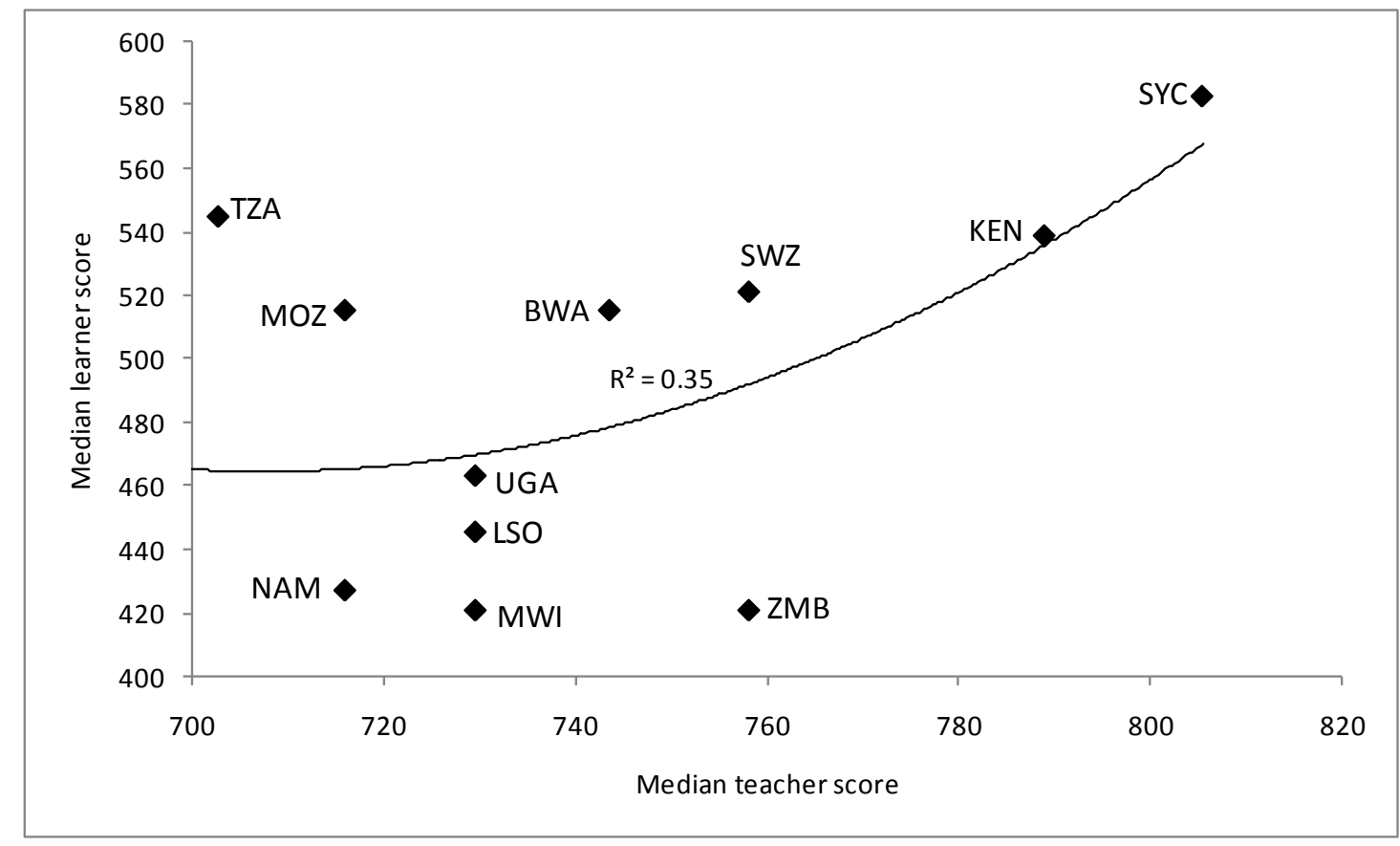

Source: IIEP: SACMEQ, 2004. Note: The two SACMEQ 2000 countries Mauritius and South Africa do not appear as in these countries teacher tests were not run, largely as a result of teacher union opposition (South Africa did, however, run the teacher tests in the 2007 run of SACMEQ).

If the relationship between teacher human capital and learner results is relatively weak, as is indicated by the graph, then it becomes less justifiable to use contemporaneous school and income data. If more dynamic factors, such as the length of the school day, or the availability of textbooks, are able to make a difference to learner performance, separately from the skills and knowledge of teachers, then there is a greater likelihood of rapid changes in the levels of learner performance, and using learner results from a later period as a proxy from an earlier period becomes less plausible. Unfortunately, there is no easy way out of this quandary as the required data on learner performance from an earlier period is not available. The best we can do is let these observations bring extra caution to our interpretation of the growth model.

The next table presents the bivariate correlations between our variables. The bivariate correlations between GDP per capita and the other variables are of particular interest. Here the exceptionally low coefficient for investment over GDP of just .04 is noteworthy, despite the fact that in the multivariate model investment will be seen to be a significant explanatory variable. This contrast is not a key concern for this paper, however. The human capital variables, except for engineering enrolment and adult literacy, all display a correlation in the range of .46 to .68 . One would not expect a very high correlation for the adult literacy 
variable, given how it is derived. The very high correlation of .98 between the two PIRLS variables is to be expected ${ }^{32}$.

Table 7: Correlations of country-level variables

\begin{tabular}{|c|c|c|c|c|c|c|c|c|c|c|}
\hline & 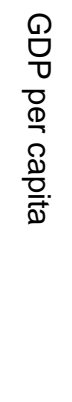 & 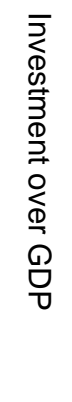 & 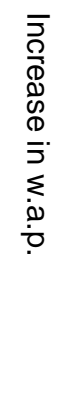 & 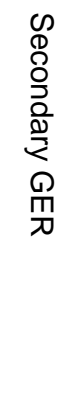 & 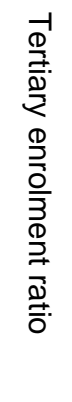 & 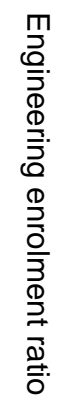 & 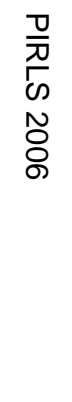 & 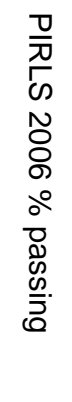 & 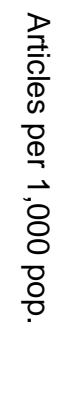 & 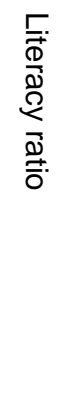 \\
\hline GDP per capita & 100 & & & & & & & & & \\
\hline Investment over GDP & 4 & 100 & & & & & & & & \\
\hline Increase in w.a.p. & -33 & -11 & 100 & & & & & & & \\
\hline Secondary GER & 68 & 19 & -65 & 100 & & & & & & \\
\hline Tertiary enrolment ratio & 55 & 3 & -49 & 77 & 100 & & & & & \\
\hline Engineering enrolment ratio & 32 & 21 & -39 & 54 & 81 & 100 & & & & \\
\hline PIRLS 2006 & 60 & -3 & -71 & 74 & 73 & 55 & 100 & & & \\
\hline PIRLS $2006 \%$ passing & 57 & -3 & -73 & 75 & 73 & 53 & 98 & 100 & & \\
\hline Articles per 1,000 pop. & 64 & -10 & -44 & 63 & 44 & 22 & 59 & 57 & 100 & \\
\hline Literacy ratio & 46 & 29 & -54 & 79 & 63 & 59 & 68 & 68 & 49 & 100 \\
\hline
\end{tabular}

Table 8 provides the results of the multivariate regression models. Models A and B replicate the Mankiw, Romer and Weil (1992) augmented Solow model with more recent data. The difference between models $\mathrm{A}$ and $\mathrm{B}$ is that $\mathrm{B}$ includes only those countries for which the PIRLS learner performance data were available - the results suggest that this substantial reduction in the number of countries, from 108 to 55, makes little difference to the model estimates. Both models exclude those countries Mankiw, Romer and Weil (1992) filtered out as they were assumed to display unusual growth trajectories: oil producers, ex-communist countries and countries with a population of less than one million. It should be noted that for the human capital variable, secondary school enrolments over the entire population aged 15 to 64 (as opposed to the secondary level GER) is used, in line with Mankiw, Romer and Weil (1992). Model B can be expressed as follows:

$$
\ln (Y)=4.78+1.19(\ln (i))-0.70(\ln (n+g+\delta))+0.91(\ln (s))
$$

The fact that the results are fairly similar to the original results confirms the robustness of that model and justifies its use as a basis for exploring the performance of our additional human capital variables. Model C is the original model with the PIRLS 'literacy rate' and the natural logarithm of the article publication variable added. All the explanatory variables display a statistically significant association with GDP per capita (at the 95\% confidence level). This is the model that is used further down to gauge the cost of illiteracy. It can be expressed as follows:

$$
\ln (Y)=6.21+0.70(\ln (i))-0.21(\ln (n+g+\delta))+0.49(\ln (s))+0.0070(\text { pirls } \%)+0.20(\ln (A))
$$

If the secondary school enrolment variable $s$ is removed, the slope coefficient of the PIRLS variable increases, but perhaps not by as much as one might anticipate - the increase is from

\footnotetext{
${ }^{32}$ Hanushek and Woessman (2007: 39) note this same pattern between the mean and the percentage achieving a low threshold score.
} 
.0070 to .0086 . In model D, the PIRLS country mean instead of the PIRLS 'literacy rate' is used. As one might expect, model D is similar to model C, though the PIRLS variable is now only significant at a $90 \%$ confidence level. Models $\mathrm{E}$ and $\mathrm{F}$ repeat model $\mathrm{C}$, but with more variables as the country filters are relaxed. In model $\mathrm{E}$ only the population filter is applied, and in model F only the oil producer filter is applied. Whilst the relaxation of these filters has little effect on the significance and slope coefficients of the human capital variables, they render the investment and demographic variables insignificant. For this reason, it was decided to retain all the original Mankiw, Romer and Weil (1992) country filters in the model (model C) used to determine the cost of illiteracy. Model G tests the use of the UNESCO adult literacy variable $r$ as the only human capital variable (it is entered in the quadratic form, and a joint significance reveals that despite the low $t$ values, jointly $r$ and $r^{2}$ are significant predictors at the $1 \%$ level). Given the way this variable is derived, it should not surprise us that the overall fit of the model, as indicated by $R^{2}$, is the lowest of all the models. Yet the fact that the literacy variable is highly significant, despite the measurement problems, suggests that standardised and more objective measures of adult literacy are likely to be extremely strong predictors of GDP per capita.

Table 8: Cross-country regression results

\begin{tabular}{|c|c|c|c|c|c|c|c|}
\hline $\begin{array}{l}\text { Dependent variable: } \ln (Y), Y \text { is } \\
\text { GDP over working age population }\end{array}$ & A & $\mathrm{B}$ & $\mathrm{C}$ & $\mathrm{D}$ & $\mathrm{E}$ & $\mathrm{F}$ & $\mathrm{G}$ \\
\hline $\ln (I), i$ is investment over GDP & $\begin{array}{c}1.04 \\
(4.47)\end{array}$ & $\begin{array}{c}1.19 \\
(3.11)\end{array}$ & $\begin{array}{c}.70 \\
(2.29)\end{array}$ & $\begin{array}{c}.73 \\
(2.39)\end{array}$ & $\begin{array}{c}.22 \\
(0.84)\end{array}$ & $\begin{array}{c}.37 \\
(1.23)\end{array}$ & $\begin{array}{c}1.02 \\
(4.28)\end{array}$ \\
\hline $\begin{array}{l}\ln (n+g+\delta), n \text { is increase in } \\
\text { working age population }^{33}\end{array}$ & $\begin{array}{c}-.79 \\
(-9.40) \\
\end{array}$ & $\begin{array}{c}-.70 \\
(-8.25) \\
\end{array}$ & $\begin{array}{c}-.21 \\
(-2.19)\end{array}$ & $\begin{array}{c}-.22 \\
(-2.36)\end{array}$ & $\begin{array}{c}.00 \\
(-0.01)\end{array}$ & $\begin{array}{c}-.03 \\
(-0.41)\end{array}$ & $\begin{array}{c}-.44 \\
(-3.22) \\
\end{array}$ \\
\hline $\begin{array}{l}\ln (s), s \text { is secondary enrolment over } \\
\text { working age population }\end{array}$ & $\begin{array}{l}.78 \\
(6.85)\end{array}$ & $\begin{array}{c}.91 \\
(6.00)\end{array}$ & $\begin{array}{c}.49 \\
(3.91)\end{array}$ & $\begin{array}{c}.52 \\
(4.15) \\
\end{array}$ & $\begin{array}{c}.42 \\
(3.08) \\
\end{array}$ & $\begin{array}{c}.46 \\
(3.53) \\
\end{array}$ & \\
\hline pirls\% is PIRLS $2006 \%$ passing & & & $\begin{array}{l}.0070 \\
(2.23)\end{array}$ & & $\begin{array}{l}.0072 \\
(2.27)\end{array}$ & $\begin{array}{l}.0090 \\
(2.78)\end{array}$ & \\
\hline PIRLS 2006 & & & & $\begin{array}{l}.0023 \\
(1.90) \\
\end{array}$ & & & \\
\hline literacy ratio & & & & & & & $\begin{array}{c}-.01 \\
(-0.67)\end{array}$ \\
\hline$r^{2}, r$ is literacy ratio & & & & & & & $\begin{array}{l}.00024 \\
(1.95)\end{array}$ \\
\hline $\ln (A), A$ is articles per 1,000 pop. & & & $\begin{array}{c}.20 \\
(3.66) \\
\end{array}$ & $\begin{array}{c}.21 \\
(3.59) \\
\end{array}$ & $\begin{array}{c}.26 \\
(4.44) \\
\end{array}$ & $\begin{array}{c}.22 \\
(3.72) \\
\end{array}$ & \\
\hline Constant & $\begin{array}{c}4.78 \\
(7.58) \\
\end{array}$ & $\begin{array}{c}4.15 \\
(3.52) \\
\end{array}$ & $\begin{array}{c}6.21 \\
(6.89) \\
\end{array}$ & $\begin{array}{l}5.44 \\
(5.90) \\
\end{array}$ & $\begin{array}{l}7.77 \\
(9.67) \\
\end{array}$ & $\begin{array}{c}7.04 \\
(7.77) \\
\end{array}$ & $\begin{array}{c}5.36 \\
(6.96) \\
\end{array}$ \\
\hline $\mathrm{N}$ & 108 & 55 & 55 & 55 & 63 & 60 & 84 \\
\hline $\mathrm{R}^{2}$ & 0.74 & 0.73 & 0.87 & 0.86 & 0.81 & 0.84 & 0.68 \\
\hline
\end{tabular}

Whilst in model $\mathrm{C}$ both the quantitative (enrolment) and qualitative (PIRLS) variables are simultaneously significant, Hanushek and Woessman (2007: 33) find that their qualitative variable renders their quantitative enrolment variable insignificant, suggesting that it is far more important to concentrate on educational quality than on enrolments in education policies. Why would the quantitative variable still appear significant in our model, beside the educational quality variable? There are a couple of possible explanations. It could be because our model includes more developing countries (in particular African ones). It could also be because the dependent variable is different - log of GDP per capita in our model whilst average annual growth rate in GDP per capita in that of Hanushek and Woessman (2007).

To facilitate the interpretation of model $\mathrm{C}$ for South African policymaking, the model is reproduced graphically below. The positions of the curve labels indicate against which

\footnotetext{
${ }^{33} \mathrm{~g}$, or growth in the level of technology, and $\delta$, or the rate of depreciation of capital goods, are retained in the model, and are assumed to add up to 0.05 for all countries, following Mankiw, Romer and Weil (1992: 414).
} 
vertical axis to read the values. Labels on the left side of the graph indicate that the curve should be read against the left-hand vertical axis, whilst labels on the right indicate that the right-hand vertical axis should be used.

\section{Figure 8: Graphical representation of the growth model}

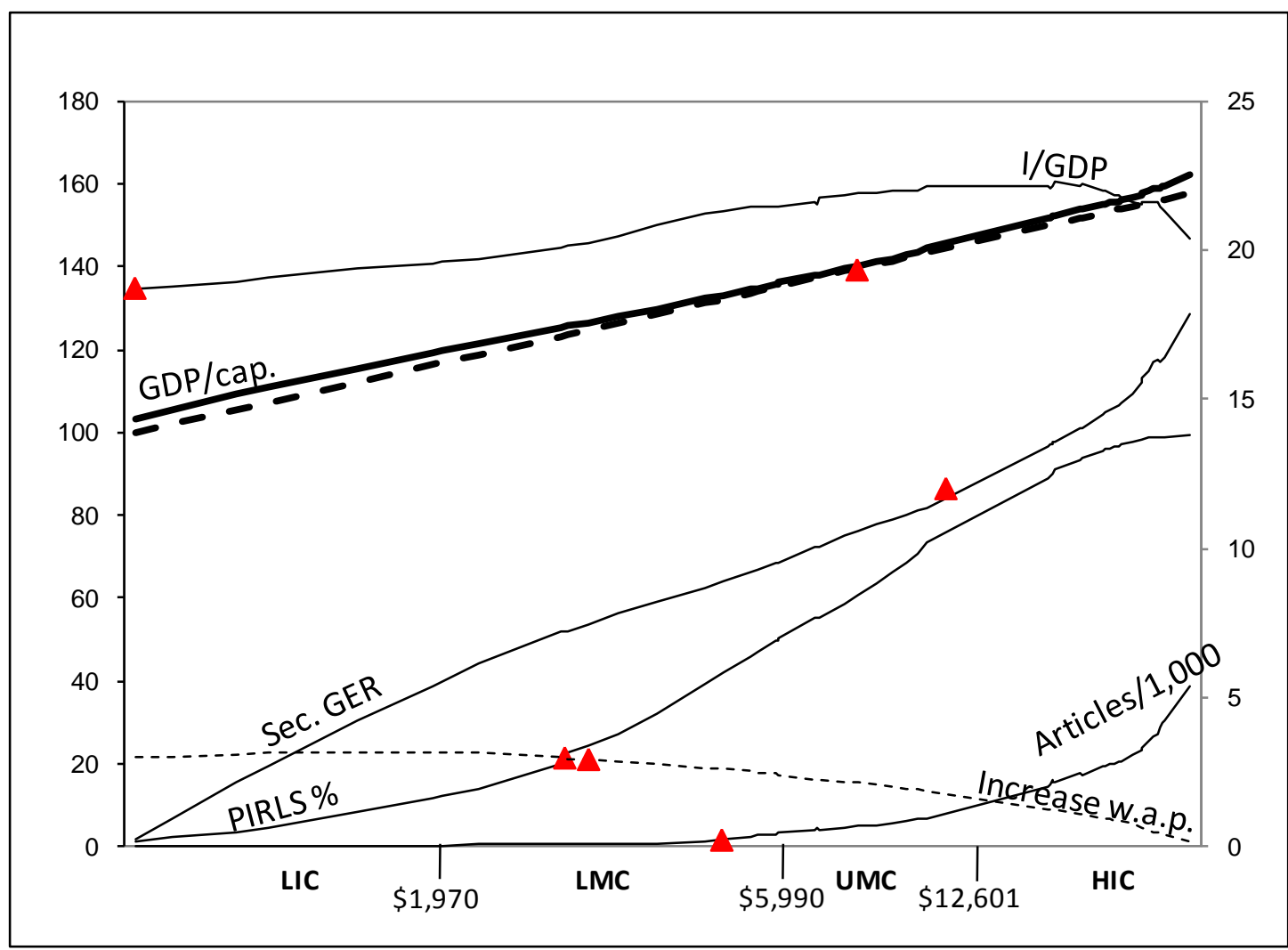

Note: The positions of curve labels indicate whether the left-hand or the right-hand axis applies. The actual GDP per capita curve (thick dotted line) is indexed to equal 100 at the lowest point. The solid thick line refers to GDP per capita estimated by the model. All GDP per capita values are expressed as natural logarithms. The cut-offs for lower income countries, lower middle income countries, upper middle income countries and high income countries are calibrated so that countries become classified as they would in the World Bank's classification (the dollar values are those of Heston, Summers and Aten, 2006). Curves are smoothed using lowess values. Triangles refer to South Africa's position. South Africa's I/GDP value, of 16, was in fact below the lowest point of the I/GDP curve, but the marker was placed at the lowest curve point of 19 to facilitate the presentation.

The implied trends over time in the country development trajectory are indicated by the curves in Figure 8, and South Africa's position on these curves is indicated using red triangles. South Africa's GDP per capita is that of an upper middle income country (UMC). Investment over GDP in the period 1990 to 2003 (the period for which the data apply) was extremely low in South Africa, at the level of a low income country (LIC). This variable has since changed. In 2007, investment over GDP was $22 \%$, or at a level befitting an upper middle income country (investment over GDP should be read against the right-hand vertical axis of the graph) $)^{34}$. The annual increase in the working age population in the 1990 to 2003 period, at 2.9\%, was higher than what was typical for a UMC. It should have been lower given that this value is expected to fall as a country develops. Again, however, Statistics South Africa data indicate that in 2008 the value was more or less where it should be (for a $\mathrm{UMC}$ ), at around $2.1 \%$ (more or less the level for Argentina) ${ }^{35}$. The secondary level gross

\footnotetext{
${ }^{34}$ Throughout our analysis, investment over GDP is gross capital formation (which includes government and private investment) over GDP.

${ }^{35}$ Mid-year population estimates for 2007 and 2008 used.
} 
enrolment ratio in South Africa for 1990 to 2003, at 86\%, was higher than one would expect of a typical upper middle income country. In fact, it was almost that of a high income country (HIC) such as the Czech Republic (92\%). By 2007, after years of strong growth, the South African ratio had reached $103 \%$, according to the 2007 Community Survey ${ }^{36}$. The number of published Springer articles for South Africa (a total of 8,749, or 0.21 per 1,000 inhabitants) is somewhat low, at a lower middle income level, when it should be at around the level enjoyed by Turkey (0.32) or Chile (0.38). Finally, the PIRLS 'literacy rate' for South Africa, at 21\%, is considerably below what it should be. It is above the expected low income country level ( $1 \%$ for Zambia or Mozambique, or $8 \%$ for Tanzania), but well below the actual levels for the three lower middle income countries that participated in PIRLS 2006: Morocco (24\%), Indonesia $(53 \%)$ and Iran $(60 \%)$. According to the model reflected in Figure 8, but even according to a more casual comparison against other countries, South Africa's PIRLS pass rate ought to be around 50\%, given the country's level of development as reflected by GDP per capita.

Figure 8, and the above discussion, imply that low educational quality stands out the critical brake on economic growth in South Africa. Enrolment in schools is clearly not a problem. But if the quality of education is an important factor behind growth, as our model suggests, and as work by analysts such as Hanushek and Woessman suggest even more strongly than we do, then investing in the improvement of educational quality should lie at the heart of South Africa's growth strategy.

These conclusions would remain essentially the same if we had used average learner performance, as opposed to percentage of learners passing some international threshold.

The model we have used allows us to calculate, very roughly, the cost of not being a more literate society. If we assume that the country's PIRLS 'literacy rate' should be $50 \%$, and that the model C slope coefficient for this variable, of .0070 (see Table 8), describes the impact of moving from the current $21 \%$ to the desired $50 \%$ 'literacy rate', then GDP per capita would be around $23 \%$ higher if we were as literate as we ought to be. If we put Rand values to this, GDP per capita in 2009 would be around R12,000 higher, and total GDP would be around R550 billion higher. This suggests one could argue that illiteracy is costing the country a large amount of income in the vicinity of R550 billion a year.

In addition to the modelling discussed here, we tried a different approach, using a microeconomic model, in order to quantify the relationship between educational quality and income. We did this partly to demonstrate how sensitive any income estimates are to one's model and one's assumption, but also to verify whether a different approach would also reveal very large benefits for improvements in educational quality. Our alternative model involved using a grade- and race-specific educational quality measure developed by Burger (2009). If we use this measure in a Mincerian earnings function, we find that an improvement of 1.07 standard deviations in the measure for adults aged 20 to 29 results in an income improvement of $30 \%$, which we can compare to the $23 \%$ GDP improvement referred to above. (The improvement in the PIRLS 'literacy rate' from $21 \%$ to $50 \%$ translates into an improvement in the mean from 302 to 429 , which represents an improvement of 1.07 standard deviations in the South African data.) The $30 \%$ level we obtain using the alternative model would translate into an annual cost of around R750 billion a year. The result confirms that that income returns to educational quality improvements are substantial enough to warrant very serious attention to the matter of quality in the country's education policies.

\footnotetext{
${ }^{36}$ The 2007 Community Survey (Stats SA, 2008) indicates that 5,299,578 youths aged 14 to 25 attended secondary school, and that the population aged 14 to 18 (five cohorts to correspond to five years of secondary schooling) was 5,130,146.
} 
Does a country necessarily have to concentrate on its weak points (educational quality in South Africa) in promoting growth, as opposed to its strong points (enrolments in South Africa)? If various factors contribute towards economic growth, does it really matter which one the country focuses on? The answer is yes. The various factors (such as enrolment and educational quality) reinforce each other. Moreover, the law of diminishing returns in economics must inform policy choices. Beyond certain threshold levels, inputs in the growth process (just like inputs in the production process in the firm) tend to diminish in potency. For instance, beyond a certain threshold, the growth impact of investments in physical capital diminish, partly because they divert resources away from other important activities, such as education. Similarly, making increased enrolments a top priority in a country such as South Africa, which already has a favourable level of school enrolments ${ }^{37}$, could divert resources and policy attention from quality improvement strategies. In the absence of some abnormal phenomenon, such as the discovery of large oil reserves in South Africa, the typical growth dynamics will apply to the country, and this means paying special attention to the growth factors that lag behind. The foregoing discussion is thus not just about what to focus on in promoting growth, but also what should probably not be a top policy priority.

Though it is not a central concern in this paper, the question of how to improve the quality of school education deserves at least a cursory discussion. It is useful to distinguish between topdown approaches and bottom-up approaches, and to emphasise that a mix of both approaches is needed. The tendency is arguably for governments and societies to pay too much attention to top-down policies, and too little attention to policies that facilitate a bottom-up approach ${ }^{38}$.

What we refer to as the top-down approach can be summed up as follows. The government and education researchers (the top) find out what interventions are most cost-effective for bringing about quality improvements, and policies (teacher incentives, textbook funding, infrastructure planning, and so on) are designed to emphasise these interventions. Much of the so-called production function literature, and the effective schools literature, are aimed at clarifying what interventions work $^{39}$. In South Africa, policies such as the school funding norms ${ }^{40}$ and the recently restructured teacher pay system $^{41}$ are explicitly constructed to improve educational quality (this is clearly the aim, though whether the construction is the right one is and ought to be the subject of ongoing debate). In order to monitor whether the top-down interventions are having the desired effect, performance statistics, such as those emerging from the Grade 12 examinations or from the Systemic Evaluation programme ${ }^{42}$ (which applies standardised tests at the primary level on a sample basis), are analysed. Topdown interventions have an important role to play, for instance where they involve the spread of new teaching methodologies that have been proven to raise learner performance within pilot projects that include control groups of schools. Such methodologies seem to have been identified in a few projects in South Africa, such as Learning for Living at the primary level and Quality Learning Project at the secondary level ${ }^{43}$.

\footnotetext{
${ }^{37}$ The South African level of enrolments at the tertiary level, on the other hand, comes out low in an international comparison, and could be linked to the relatively low performance of South Africa with respect to our journal article publications variable. This is a vital matter for growth, but does not receive detailed attention here as our focus is on illiteracy, or problems at the lower end of the educational range.

${ }^{38}$ Hoenack (1996: 332) makes this argument, but using different terminology.

${ }^{39}$ Christie, Butler and Potterton (2007) provide an example of a South African effective schools analysis. Gustafsson (2007) provides a brief account of recent education production function studies for South Africa.

${ }^{40}$ Government Notice 869 of 2006 (see http://www.gov.za/).

${ }^{41}$ Resolution 1 of 2008 of the Education Labour Relations Coucil (see http://www.elrc.org.za)

${ }^{42}$ See for instance Department of Education (2005).

${ }^{43}$ See Schollar (2005) and Kanjee and Prinsloo (2005).
} 
The bottom-up approach aims to harness parent demands for quality education, and the innovation of teachers to bring about quality improvements. To some extent, this approach involves leaving it up to the teachers themselves to work out what improves educational quality. But it by no means condemns government and researchers to inaction. Rather, it shifts the emphasis of national efforts to two key things. Firstly, having national quality standards, tools for teachers themselves to test attainment of those standards and regular and sufficiently widespread standardised assessments organised by the authorities become important. Secondly, parents need to be targeted with very clear information on what constitutes quality education, on how well their children are faring, and on the mechanisms for complaining about the quality of their children's education. In South Africa, the Grade 12 examinations provide a powerful accountability tool at the end of the secondary level, but as has often been argued, the country lacks such tools at lower levels of the system. The Systemic Evaluation, whilst it is an essential programme for monitoring the system as a whole and follows best practice in other developing countries, is not able to provide individual schools and teachers with feedback on their performance, because it is based on a sample. A programme such as the Systemic Evaluation is almost certainly too costly to replicate across all schools without compromising on the rigour of the data collection (it is essentially a programme designed to support the top-down approach). The challenge facing developing countries is thus to design cheaper programmes that can assess learners, perhaps with less (but sufficient) rigour, and on a massive scale. South Africa's national Foundations of Learning programme ${ }^{44}$, which involves the distribution of testing packs to schools, has the potential to fill this gap and to provide parents with an easily intelligible method of following their children's performance and exerting the right kind of pressure when schools under-perform. It is worth underlining that without assessments that are standardised across schools (this has been the norm in primary schools in South Africa up till now) and without good feedback mechanisms to parents, it is virtually impossible for parents to know how much improvement they can legitimately and reasonably demand of their schools. The success of government programmes such as Foundations of Learning (and similar assessment programmes implemented by NGOs) is a vital factor impacting on future income and welfare in South Africa.

To end this section, a look at the distribution of the PIRLS 2006 scores of a few countries (just actual PIRLS scores, not the imputed ones used in the earlier analysis) throws some light on key specifics of the quality challenge facing South Africa. The countries included in the following graph are the only four large developing countries that participated in PIRLS 2006, namely Indonesia, Iran, Morocco and South Africa, plus one developed country that participated, namely New Zealand.

\footnotetext{
${ }^{44}$ Government Notice 306 of 2008 (see http://www.gov.za/).
} 
Figure 9: PIRLS 2006 score distributions for a few countries

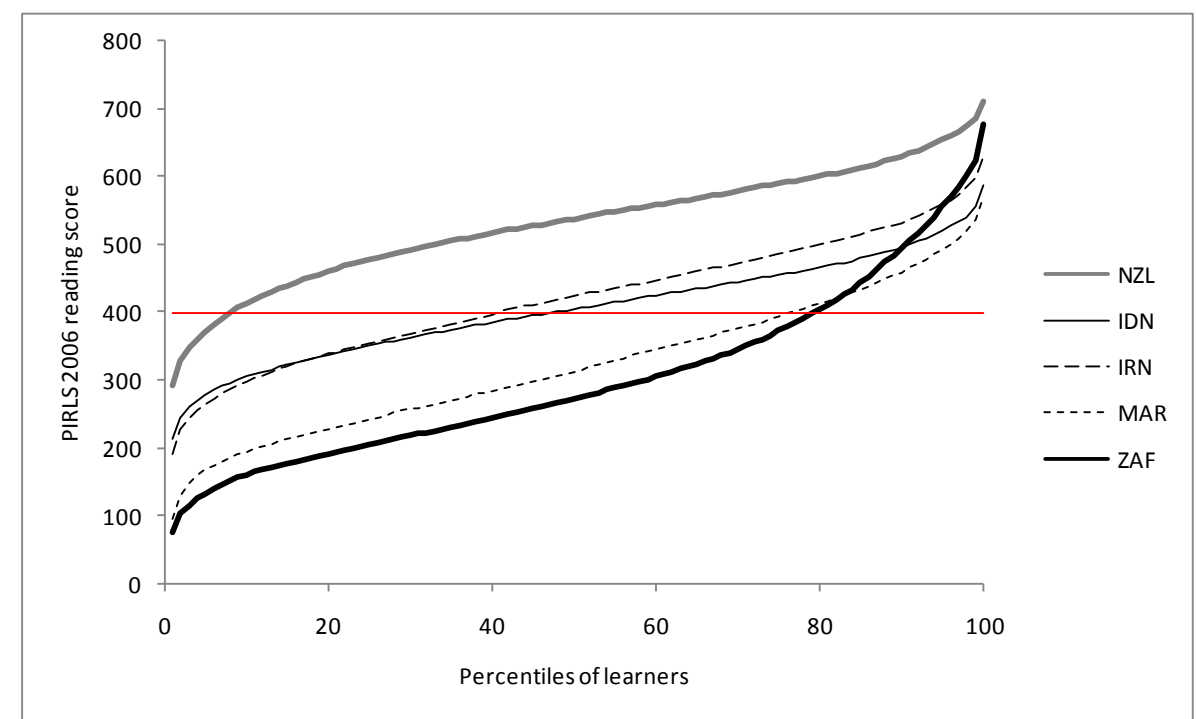

Source: IEA, 2007.

The need to improve the quality of education for the worst performers, largely the poor, is confirmed by the low position of South Africa's curve in the left-hand two-thirds (at least) of the above graph. But the extent of the problem (79\% of learners do not attain the 400 low international benchmark) suggests strongly that policy focus needs to be largely on systemic solutions, as opposed to the targeting of poorly performing pockets of the system (an approach that would be more appropriate for a country like New Zealand, where only $7 \%$ of learners do not reach the benchmark). At the very top end of the performance range in South Africa, scores are relatively good compared to those of the other developing countries in the graph. This means that pockets of rather good practice can be found within the country, which can serve to inform improvements in the rest of the system. However, it is also important to stress that the best practice pocket is dangerously small in South Africa, and needs to be expanded. Only $5 \%$ of learners at the top end perform slightly better than those of Iran. To the left of the $95^{\text {th }}$ percentile, the South African curve drops steeply. It is probably true to say that the popular perception in South Africa is that the country's best schools (whether public or independent ${ }^{45}$ ) are on a par with the best schools in developed countries. A comparison between the curves of South Africa and New Zealand, however, would suggest that this is not the case, and that improvement strategies should focus even at the top end ${ }^{46}$. This should strengthen the argument for system-wide solutions that include a focus on factors common to the whole system, such as textbooks.

\footnotetext{
${ }^{45}$ The PIRLS sample includes independent schools.

${ }^{46}$ A similar picture of relatively poor performance at the top end emerges if one compares the scores of the learners whose parents are university graduates across countries, as is done by Reddy (2006: 88) in analysing the 2003 TIMSS dataset.
} 


\section{Conclusion}

The executive summary provides a section by section summary of the paper. Here the focus is on identifying what may be the principal findings of the paper, and what the key pointers are for policymaking and future data collection and analysis.

The paper throws some new light on the unreliability of self-reported measures of adult literacy, and suggests that instead of the $90 \%$ adult literacy rate obtained from these measures, a figure closer to $75 \%$, more or less the percentage of adults who spend at least an hour a week reading, should be used as an adult literacy rate for the country. Literacy rates based on highest grade passed in the schooling system, whilst in certain contexts somewhat useful as proxies for the true literacy rate, need to be calculated and interpreted with caution given that different grade attainment levels bring about literacy for different people (one person may require a Grade 4 to be literate, whilst another may require a Grade 7). But it is important to stress that given the lack of test-based data on adult literacy in South Africa, the best we can do currently is arrive at tentative estimates of the adult literacy rate. Even so, it seems that we can conclude that officially published adult literacy rates (in particular UNESCO's 88\%) are over-estimates. Going forward, policymakers and researchers should pay attention to how South Africa can obtain nationally representative objective measures of adult literacy. There are a number of options available, and these need to be assessed carefully. Slotting into an existing international adult literacy monitoring programme, in particular ALL or LAMP, is an option (though ALL appears to have no other developing country participants). Designing a national programme, informed by experiences in the international programmes, and on national experiences such as those in Kenya, is another option. The cost of the data collection would be small, especially in comparison to current budgets for adult illiteracy programmes, yet probably large enough to make central government funding necessary.

But within a long-range perspective, what is perhaps even more important than research into adult literacy, is research into optimal methods for using data on learner performance below the Grade 12 level to drive quality improvement in schools (and hence reduce adult illiteracy in the future). Major strides on the data collection front have been made in the last ten years, through participation in international programmes, and through the country's own Systemic Evaluation programme. We have a much better picture of where South Africa's school quality is pegged internationally, and what the distribution of learner performance is within the country. Currently, our knowledge of average learner performance down to the province level is good. However, below this level, at the level of districts and schools, our understanding is poor. Yet it is local level performance data that is likely to be most useful for schools and district offices, where much of the improvement effort must be concentrated. As has been argued in section 6, effective performance measurement at the local level probably requires different instruments to what one has at a national or international level, given the cost factors. Of course arriving at optimal data collection strategies is only one part of the problem. The other is arriving at optimal strategies for using the data to stimulate a local commitment towards improving educational quality.

The paper found literacy effects at the individual level. For instance, the literacy of parents (and their behaviour, such as their reading behaviour) displays a large association with learner literacy (the magnitude of parent factors, relative to that of other factors, is arguably larger than is commonly believed). Literacy is associated with self-reported satisfaction, and health, and with a healthy questioning of those in political power, and political parties generally. A better understanding of why literacy is important depends to a large degree on obtaining better measures of adult literacy. For this area of research data collections limited to localised samples are often good enough, and are less costly and less complicated to realise than nationally representative collections. 
The finding that illiteracy costs the country R550 billion per year in income (and GDP), whilst perhaps not a finding of a directly practical nature, is nonetheless useful as an indicator of the magnitude of the literacy challenge in the larger development debate. What should be emphasised in this regard is the finding that within the overall economic growth picture (obtained using standard cross-country modelling), education is clearly a laggard factor. In respect of other typically analysed growth factors, South Africa does fairly well, but in respect of education it does not. There is room for much more research and public debate on the linkages between education policies and the growth and development policies. In particular, the right balance between general education and specialised vocational education needs more attention, as does the right balance between uplifting the educational quality of the worst performers in the schooling system and uplifting the educational quality of everyone. It goes without saying that part of the debate should be about the right balance between economic growth, in the traditional sense, and broader development indicators such as the UNDP's Human Development Index (HDI) and even life satisfaction indicators such as those found in the World Values Survey. 


\section{References}

Aitchison, J. \& Harley, A. (2004). South African illiteracy statistics and the case of the magically growing number of literacy and ABET learners. Durban: University of KwaZulu-Natal. Available from: 〈http://www.ukzn.ac.za/cae/caepubs/JJWAAH04.pdf〉 [Accessed June 2009].

Barro, R.J. \& Lee, J.-W. (2001). International data on educational attainment (dataset). Cambridge: Harvard University.

Benhabib, J. \& Spiegel, M.M. (1994). The role of human capital in economic development: Evidence from aggregate cross-country data. Journal of Monetary Economics, 34: 143173.

Bils, M. \& Klenow, P.J. (2000). Does schooling cause growth? Journal of Economic Growth, 90(5): 1160-1183.

Boissiere, M., Knight, J.B. \& Sabot, R.H. (1985). Earnings, schooling, ability and cognitive skills. The American Economic Review, 75(5): 1016-1030.

Burger, C. (2009). Role of school quality in labour market discrimination in South Africa. Oxford: Centre for the Study of African Economies. Available from:

<http://www.csae.ox.ac.uk/conferences/2009-EDiA/papers/435-Burger.pdf> [Accessed May 2009].

Christie, P., Butler, D. \& Potterton, M. (2007). Schools that work. Pretoria: Independent Schools Association of South Africa. Available from:

<http://www.isasa.org/component/option,com_docman/task,doc_view/gid,531/Itemid,27/ $>$ [Accessed January 2008].

Department of Education (1999). Call to action: Mobilising citizens to build a South African education and training system for the 21st century. Pretoria. Available from: <http://www.capegateway.gov.za/Text/2004/5/tirisanocalltoaction.pdf> [Accessed March 2009].

Department of Education (2005). Grade 6 Systemic Evaluation: National. Pretoria. Available from:

<http://www.hsrc.ac.za/research/output/outputDocuments/3580_Grade6National.pdf> [Accessed February 2006].

Department of Education (2006). PFMA planning and reporting requirements for Provincial Education Departments. Pretoria. Available from:

$<$ http://www.education.gov.za/dynamic/dynamic.aspx?pageid=326\&dirid=20> [Accessed April 2008].

Department of Education (2007). Plan for a mass literacy campaign for South Africa. Pretoria.

Department of Education (2008). Ministerial Committee on learner retention in the South African schooling system. Pretoria. Available from: 〈http://www.education.gov.za> [Accessed April 2008].

Gustafsson, M. (2007). Using the hierarchical linear model to understand school production in South Africa. Stellenbosch: University of Stellenbosch. Available from: <http://ideas.repec.org/p/sza/wpaper/wpapers32.html> [Accessed February 2007].

Gustafsson, M. \& Patel, F. (2006). Undoing the apartheid legacy: Pro-poor spending shifts in the South African public school system. Perspectives in Education, 24(2): 65-77.

Gustafsson, M. \& Patel, F. (2008). Managing the teacher pay system: What the local and international data are telling us. Cape Town: DPRU. Available from:

<http://www.commerce.uct.ac.za/Research_Units/DPRU/Conference2008/Conference200 8_Papers/Gustafsson\%20-Teacher\%20pay\%20system\%202008\%2010\%2005.pdf> [Accessed March 2009].

Hanushek, E.A. \& Kimko, D.D. (2000). Schooling, labor-force quality and the growth of nations. The American Economic Review, 90(5): 1184-1208.

Hanushek, E.A. \& Luque, J.A. (2003). Efficiency and equity in schools around the world. Economics of Education Review, 22: 481-502. 
Hanushek, E.A. \& Woessman, L. (2007). The role of school improvement in economic development. Washington: National Bureau of Economic Research. Available from: <http://papers.nber.org/papers/w12832.pdf?new_window=1> [Accessed June 2007].

Hanushek, E.A. \& Woessman, L. (2009). Do better schools lead to more growth? Cognitive skills, economic outcomes, and causation. Washington: National Bureau of Economic Research. Available from: <http://www.nber.org/papers/w14633.pdf?new_window=1> [Accessed March 2009].

Heston, A., Summers, R. \& Aten, B. (2006). Penn World Table version 6.2. Philadelphia: Center for International Comparisons of Production, Income and Prices at the University of Pennsylvania. Available from: 〈http://pwt.econ.upenn.edu/php_site/pwt_index.php> [Accessed June 2007].

Hoenack, S.A. (1996). The economics of education in developing countries: An assessment of the state of the art. Economics of Education Review, 15(4): 327-338.

IEA (2004). TIMSS 2003 (dataset). Chestnut Hill: Boston College. Available from: <http://timss.bc.edu/timss2003.html> [Accessed July 2007].

IEA (2007). PIRLS 2006 (dataset). Chestnut Hill: Boston College. Available from: $<$ http://timss.bc.edu/pirls2006/index.html> [Accessed June 2008].

IIEP: SACMEQ (2004). SACMEQ II (2000 dataset). Harare.

Kanjee, A. \& Prinsloo, K. (2005). Improving learning in South African schools: The Quality Learning Project (QLP). Pretoria: HSRC. Available from: <http://www.hsrcpress.ac.za> [Accessed May 2009].

Keswell, M. \& Poswell, L. (2004). Returns to education in South Africa: A retrospective sensitivity analysis of the available evidence. South African Journal of Economics, 72(4): 834-860.

Lauglo, J. (2001). Engaging with adults: The case for increased support to adult basic education in Sub-Saharan Africa. Washington: World Bank. Available from: $<$ http://www.eric.ed.gov/ERICDocs/data/ericdocs2sql/content_storage_01/0000019b/80/1 a/8b/4f.pdf > [Accessed March 2009].

Malhotra, A., Pande, R. \& Grown, C. (2003). Impact of investments in female education on gender equality. Washington: World Bank. Available from:

$<\mathrm{http} / / /$ siteresources.worldbank.org/INTGENDER/Resources/ImpactInvestmentsFemaleE du.pdf> [Accessed June 2008].

Mankiw, N.G., Romer, D. \& Weil, D.N. (1992). A contribution to the empirics of economic growth. Quarterly Journal of Economics, 107(2): 407-443.

Mullis, I.V.S., Martin, M.O., Kennedy, A.M. \& Foy, P. (2007). PIRLS 2006 international report. Chestnut Hill: Boston College. Available from: <http://timss.bc.edu> [Accessed April 2007].

National Treasury (2009). 2009 Estimates of National Expenditure. Pretoria. Available from: $<$ http://www.treasury.gov.za> [Accessed June 2005].

Naudé, W.A. (2004). The effect of policy, institutions and geography on economic growth in Africa: An econometric study based on cross-section and panel data. Journal of International Development, 16: 821-849.

OECD (2001). PISA 2000 database (dataset). Paris. Available from: $<$ http://www.oecd.org/document/48/0,3343,en_32252351_32236159_33668528_1_1_1_1, 00.html > [Accessed July 2007].

OECD (2004). PISA 2003 database (dataset). Paris. Available from: <http://www.oecd.org/document/0/0,3343,en_32252351_32236173_33694144_1_1_1_1,0 0. html> [Accessed July 2007].

Oxenham, J. (2004). Adult education and training (ABET) vs. poverty: What have we learned? Benoni: Kitso Training and Development. Available from: <http://www.kitsotraining.co.za/abet\%20vs\%20poverty.pdf> [Accessed January 2009].

Psacharapoulos, G. \& Patrinos, H.A. (2002). Returns to investment in education: A further update. Washington: World Bank. Available from: 〈http://www.worldbank.org> [Accessed November 2006]. 
Pritchett, L. (1996). Where has all the education gone? Washington: World Bank. Available from: <http://www.worldbank.org> [Accessed January 2009].

Reddy, V. (2006). Mathematics and science achievement at South African schools in TIMSS 2003. Pretoria: HSRC. Available from: <http://www.hsrcpublishers.ac.za> [Accessed July 2006].

Romer, P.M. (1989). Human capital and growth: Theory and evidence. Washington: National Bureau of Economic Research. Available from: 〈http://www.nber.org/papers/w3173> [Accessed April 2007].

Sachs, J.D. \& Warner, A.M. (1997). Sources of slow growth in African economies. Journal of African Economies, 6(3): 335-376.

Schollar, E. (2005). The evaluation of the Learning for Living Project. Johannesburg:

Business Trust. Available from:

<http://www.jet.org.za/documents/Schollar.pdf\#search=\%22\%22learning\%20for\%20livin g\%22\%20\%22south\%20africa\%22\%22> [Accessed September 2006].

Sen, A. (1999). Development as freedom. New York: Alfred A. Knopf.

Solow, R.M. (1956). A contribution to the theory of economic growth. Quarterly Journal of Economics, 70(1): 65-94.

Springer (2009). AuthorMapper (dataset). Berlin. Available from: <http://authormapper.com> [Accessed March 2009].

Statistics South Africa (2007). Labour Force Survey 2007b (dataset). Pretoria. [Earlier datasets in this series also used.]

Statistics South Africa (2008). Community Survey 2007 unit records (dataset). Pretoria.

UN Population Division (2009). World population prospects: The 2006 revision (dataset). New York. Available from: <http://esa.un.org/unpp/index.asp>

UN Statistics Division (2009). National accounts estimates of main aggregates (dataset). New York. Available from: <http://data.un.org>

UNDP (2007). Human Development Report 2007/2008: Fighting climate change: Human solidarity in a divided world. New York Available from: 〈http://www.undp.org> [Accessed March 2008].

UNESCO (1990). World Declaration on Education for All. Jomtien Available from: <http://www.unesco.org/education/efa/ed_for_all/background/jomtien_declaration.shtml> [Accessed March 2009].

UNESCO (2000). The Dakar Framework for Action. Dakar Available from: <http://unesdoc.unesco.org/images/0012/001211/121147E.pdf> [Accessed March 2009].

UNESCO (2005a). Education for All global monitoring report 2005: The quality imperative. Paris Available from: 〈http://www.unesco.org/education/gmr_download/chapter2.pdf> [Accessed May 2008].

UNESCO (2005b). Education for All global monitoring report 2006: Literacy for life. Paris Available from: <http://www.unesco.org> [Accessed November 2006].

UNESCO (2005c). Standards and guidelines for the design and implementation of the Literacy Assessment and Monitoring Programme (LAMP). Montreal: UIS. Available from: <http://www.unesco.org> [Accessed November 2006].

UNESCO (2006). Education for All global monitoring report 2007: Solid foundations. Paris Available from: <http://www.unesco.org> [Accessed March 2007].

UNESCO (2007). Education for All global monitoring report 2008: Will we make it? Paris Available from: <http://www.unesco.org> [Accessed February 2008].

UNESCO (2009). Education for All global monitoring report 2009: Overcoming inequality: Why governance matters. Paris Available from: 〈http://www.unesco.org> [Accessed March 2009].

UNESCO: UIS (2009). Education statistics (dataset). Montreal. Available from: $<$ http://www.uis.unesco.org/ev_en.php?URL_ID=3753\&URL_DO=DO_TOPIC\&URL_S ECTION=201>

UNESCO: UIS (2003). Education indicators: Technical guidelines. Paris. Available from: $<$ http://www.uis.unesco.org> [Accessed January 2005]. 
Van der Berg, S. (2007). Apartheid's enduring legacy: Inequality in education. Journal of African Economies, 16(5): 849-880.

Van der Berg, S. \& Louw, M. (2008). Lessons learnt from SACMEQ. In G. Bloch, L. Chisholm, B. Fleisch and M Mabizela (ed.), Investment choices for South African education. Johannesburg: Witwatersrand University Press.

World Values Survey Association (2008). World Values Survey 2005 official data file (dataset). Madrid Available from: <www.worldvaluesurvey.org> [Accessed February 2009]. 


\section{Appendix A}

The following steps were followed to derive PIRLS-like data for 46 countries that did not have original 2006 PIRLS data.

- Firstly, the relationship between the 25 country averages of TIMSS 2003 mathematics and PIRLS 2006 (where countries participated in both) was examined graphically. Three different linear relationships were defined, on the basis of a visual examination of the non-linearities in the graph. The first was for a low performance group (in the range South Africa to Morocco, using the TIMSS averages), the second for a middle performance group (Morocco to Moldova), and the third for a high performance group (Moldova to Singapore). Each of the three linear relationships was defined using an OLS regression. The three sets of coefficients were used to translate TIMSS scores to PIRLS-like scores for the 20 countries participating in TIMSS but not PIRLS.

- Secondly, one set of OLS regression coefficients for the relationship between SACMEQ 2000 (reading) and PIRLS 2006 was found using South Africa and Botswana as the linking countries, but using the PIRLS-like score for Botswana obtained from the previous step (this was necessary as South Africa was the only country that participated in both SACMEQ 2000 and PIRLS 2006). The coefficients were used to translate the SACMEQ scores of the remaining 11 countries to PIRLS-like scores.

- Thirdly, the relationship between the 38 country averages of PISA reading and PIRLS 2006 (where countries participated in both) was examined graphically. PISA 2000 and PISA 2003 scores were used. Where countries had PISA scores for both years, the average of the two was used. Two different linear relationships were defined. The first was for a lower performance group (Indonesia to Slovakia, using the PISA averages), and the second for a higher performance group (Slovakia to the United States). Each of the two linear relationships was defined using an OLS regression. The two sets of coefficients were used to translate PISA scores to PIRLS-like scores for the 10 countries participating in PISA but not PIRLS.

- The relevant PIRLS-like average score for each of the 46 countries was determined as follows. If the country had TIMSS data, but no PISA or SACMEQ data, then the PIRLSlike score derived from TIMSS was used. Else, the PIRLS-like score derived from the PISA or SACMEQ scores was used (no country participated in both SACMEQ and PISA).

- Finally, a PIRLS-like score per performance percentile within each of the 46 countries had to be calculated. Breakdowns by percentile using the TIMSS, SACMEQ and PISA data were first produced, using whatever data each country had available. These breakdowns were translated into PIRLS-like breakdowns using in the case of each country the coefficients that had been used to calculate the PIRLS-like country average. The selection procedure described in the previous bullet was applied to decide which PIRLS-like breakdown to use for the analysis. 


\section{Appendix B}

This table provides values for the 55 countries entered in models B, C and D.

Table 9: Data for core set of countries

\begin{tabular}{|c|c|c|c|c|c|c|c|c|c|c|c|}
\hline ISO code & Country & $\begin{array}{c}\text { GDP per } \\
\text { capita }\end{array}$ & $\begin{array}{c}\text { Investment } \\
\text { over GDP }\end{array}$ & $\begin{array}{c}\text { Increase in } \\
\text { w.a.p. }\end{array}$ & $\begin{array}{c}\text { Secondary } \\
\text { GER }\end{array}$ & $\begin{array}{c}\text { Tertiary } \\
\text { enrolment } \\
\text { ratio }\end{array}$ & $\begin{array}{c}\text { Engineering } \\
\text { enrolment } \\
\text { ratio }\end{array}$ & $\begin{array}{l}\text { PIRLS } \\
2006\end{array}$ & $\begin{array}{c}\text { PIRLS } \\
2006 \% \\
\text { passing }\end{array}$ & $\begin{array}{c}\text { Articles per } \\
\text { 1,000 pop. }\end{array}$ & $\begin{array}{c}\text { Literacy } \\
\text { ratio }\end{array}$ \\
\hline ARG & Argentina & 10,511 & 16.8 & 1.5 & 75 & 54.2 & 5.1 & 461 & 67 & 0.30 & 97 \\
\hline AUS & Australia & 23,748 & 23.4 & 1.4 & 134 & 50.8 & 5.7 & 548 & 100 & 2.88 & \\
\hline AUT & Austria & 24,782 & 22.4 & 0.5 & 103 & 31.0 & 4.5 & 539 & 98 & 6.63 & \\
\hline BEL & Belgium & 22,766 & 19.9 & 0.1 & 141 & 35.9 & 4.1 & 535 & 97 & 2.98 & \\
\hline BRA & Brazil & 6,951 & 17.1 & 2.3 & 71 & 19.7 & 1.8 & 437 & 61 & 0.14 & 86 \\
\hline BWA & Botswana & 6,508 & 27.0 & 3.6 & 63 & 4.5 & 0.2 & 319 & 5 & 0.13 & 75 \\
\hline CAN & Canada & 23,939 & 19.2 & 1.1 & 104 & 42.1 & 4.3 & 550 & 98 & 3.11 & \\
\hline $\mathrm{CHE}$ & Switzerland & 27,624 & 23.4 & 0.7 & 97 & 23.5 & 3.4 & 539 & 100 & 7.82 & \\
\hline $\mathrm{CHL}$ & Chile & 10,119 & 23.6 & 1.8 & 75 & 34.8 & 11.6 & 450 & 67 & 0.38 & 95 \\
\hline DNK & Denmark & 25,288 & 19.1 & 0.3 & 120 & 37.0 & 3.7 & 542 & 97 & 4.36 & \\
\hline EGY & Egypt & 4,066 & 17.5 & 2.6 & 80 & 37.9 & & 369 & 44 & 0.14 & 56 \\
\hline ESP & Spain & 17,566 & 23.7 & 0.7 & 113 & 46.2 & 7.7 & 524 & 94 & 1.21 & 96 \\
\hline FIN & Finland & 20,138 & 19.2 & 0.2 & 121 & 54.5 & 14.0 & 554 & 100 & 3.71 & \\
\hline FRA & France & 23,079 & 19.1 & 0.4 & 108 & 35.2 & & 531 & 96 & 1.87 & \\
\hline GBR & United Kingdom & 22,382 & 17.4 & 0.2 & 111 & 36.9 & 3.4 & 545 & 100 & 2.67 & \\
\hline $\mathrm{GHA}$ & Ghana & 1,252 & 20.4 & 3.2 & 37 & 3.6 & 0.5 & 304 & 0 & 0.03 & 58 \\
\hline GRC & Greece & 13,131 & 20.0 & 0.9 & 94 & 44.9 & 6.9 & 532 & 100 & 1.47 & 94 \\
\hline HKG & Hong Kong & 25,977 & 27.2 & 1.6 & 80 & 23.6 & 4.1 & 555 & 99 & 1.03 & \\
\hline IDN & Indonesia & 3,635 & 23.0 & 2.3 & 51 & 16.3 & & 405 & 53 & 0.01 & 82 \\
\hline IRL & Ireland & 19,629 & 19.6 & 1.3 & 110 & 45.9 & 5.3 & 547 & 100 & 2.62 & \\
\hline ISR & Israel & 19,700 & 21.5 & 3.0 & 90 & 51.6 & 9.4 & 509 & 85 & 4.92 & \\
\hline ITA & Italy & 21,120 & 20.1 & 0.1 & 92 & 32.0 & 5.3 & 543 & 99 & 1.79 & 98 \\
\hline JOR & Jordan & 3,722 & 25.3 & 4.9 & 64 & 39.7 & 5.5 & 412 & 53 & 0.30 & 90 \\
\hline JPN & Japan & 23,185 & 27.5 & 0.3 & 100 & 31.7 & 5.6 & 543 & 100 & 1.12 & \\
\hline KEN & Kenya & 1,277 & 16.1 & 4.0 & 32 & 3.4 & 0.6 & 334 & 13 & 0.07 & 74 \\
\hline KOR & Korea & 13,644 & 34.0 & 1.5 & 94 & 68.6 & 23.4 & 549 & 100 & 0.64 & \\
\hline LBN & Lebanon & 5,083 & 28.6 & 2.4 & 77 & 38.1 & 4.6 & 434 & 58 & 0.23 & \\
\hline MAR & Morocco & 3,754 & 23.9 & 2.6 & 40 & 11.2 & 0.4 & 323 & 24 & 0.05 & 42 \\
\hline
\end{tabular}




\begin{tabular}{|c|c|c|c|c|c|c|c|c|c|c|c|}
\hline ISO code & Country & $\begin{array}{c}\text { GDP per } \\
\text { capita }\end{array}$ & $\begin{array}{c}\text { Investment } \\
\text { over GDP }\end{array}$ & $\begin{array}{c}\text { Increase in } \\
\text { w.a.p. }\end{array}$ & $\begin{array}{c}\text { Secondary } \\
\text { GER }\end{array}$ & $\begin{array}{c}\text { Tertiary } \\
\text { enrolment } \\
\text { ratio }\end{array}$ & $\begin{array}{c}\text { Engineering } \\
\text { enrolment } \\
\text { ratio }\end{array}$ & $\begin{array}{r}\text { PIRLS } \\
2006\end{array}$ & $\begin{array}{c}\text { PIRLS } \\
2006 \% \\
\text { passing }\end{array}$ & $\begin{array}{c}\text { Articles per } \\
\text { 1,000 pop. }\end{array}$ & $\begin{array}{c}\text { Literacy } \\
\text { ratio }\end{array}$ \\
\hline MEX & Mexico & 7,403 & 19.2 & 2.7 & 65 & 22.3 & 3.9 & 452 & 66 & 0.11 & 89 \\
\hline MKD & Macedonia & 5,036 & 16.8 & 0.8 & 69 & 20.7 & 4.1 & 422 & 65 & 0.07 & 95 \\
\hline MOZ & Mozambique & 1,102 & 21.9 & 2.2 & 7 & 0.8 & & 316 & 1 & 0.00 & 39 \\
\hline MUS & Mauritius & 13,153 & 25.7 & 1.5 & 67 & 10.3 & 1.7 & 328 & 27 & 0.07 & 82 \\
\hline MWI & Malawi & 765 & 17.9 & 3.4 & 20 & 0.4 & 0.1 & 263 & 0 & 0.02 & 64 \\
\hline MYS & Malaysia & 9,757 & 32.5 & 3.2 & 62 & 28.4 & 7.3 & 519 & 100 & 0.13 & 86 \\
\hline NAM & Namibia & 4,981 & 21.5 & 4.1 & 58 & 7.3 & 0.3 & 275 & 3 & 0.06 & 80 \\
\hline NLD & Netherlands & 23,693 & 21.5 & 0.6 & 127 & 32.4 & 3.4 & 547 & 100 & 3.97 & \\
\hline NOR & Norway & 29,666 & 20.0 & 0.6 & 114 & 44.8 & 3.1 & 519 & 93 & 3.21 & \\
\hline NZL & New Zealand & 19,146 & 20.4 & 1.2 & 107 & 49.2 & 3.2 & 540 & 92 & 2.63 & \\
\hline PER & Peru & 3,956 & 20.1 & 2.4 & 76 & 35.0 & & 339 & 31 & 0.03 & 87 \\
\hline $\mathrm{PHL}$ & Philippines & 3,399 & 21.1 & 2.8 & 78 & 34.7 & 4.4 & 321 & 0 & 0.02 & 93 \\
\hline POL & Poland & 7,377 & 19.8 & 0.6 & 96 & 45.0 & 6.1 & 528 & 93 & 0.89 & 99 \\
\hline PRT & Portugal & 15,607 & 24.6 & 0.5 & 100 & 38.0 & 7.7 & 532 & 100 & 0.79 & 88 \\
\hline SVN & Slovenia & 16,170 & 22.8 & 0.6 & 97 & 46.5 & 8.2 & 522 & 95 & 1.51 & 100 \\
\hline SWE & Sweden & 22,895 & 17.2 & 0.4 & 131 & 42.0 & 7.8 & 547 & 98 & 4.88 & \\
\hline SYR & Syria & 1,877 & 21.8 & 4.0 & 46 & & & 318 & 0 & 0.03 & 83 \\
\hline THA & Thailand & 6,309 & 32.3 & 1.9 & 51 & 35.4 & & 472 & 76 & 0.08 & 93 \\
\hline TTO & Trinidad and Tobago & 11,740 & 20.1 & 1.4 & 76 & 7.6 & 1.1 & 436 & 64 & 0.07 & 97 \\
\hline TUN & Tunisia & 6,257 & 25.3 & 2.7 & 63 & 23.2 & 2.7 & 403 & 52 & 0.15 & \\
\hline TUR & Turkey & 5,275 & 22.6 & 2.6 & 62 & 26.3 & 3.7 & 494 & 77 & 0.32 & 79 \\
\hline TZA & Tanzania & 667 & 20.6 & 3.2 & 5 & 0.8 & 0.1 & 334 & 8 & 0.03 & 69 \\
\hline UGA & Uganda & 922 & 16.8 & 3.2 & 14 & 2.9 & 0.2 & 296 & 11 & 0.02 & 62 \\
\hline URY & Uruguay & 9,774 & 13.1 & 0.7 & 91 & 30.2 & & 485 & 71 & 0.27 & 97 \\
\hline USA & United States & 30,844 & 18.0 & 1.0 & 95 & 54.1 & & 540 & 96 & 2.32 & \\
\hline ZAF & South Africa & 7,818 & 16.0 & 2.9 & 86 & 16.2 & 1.2 & 302 & 21 & 0.21 & 82 \\
\hline $\mathrm{ZMB}$ & Zambia & 932 & 14.9 & 2.9 & 25 & 2.6 & & 270 & 1 & 0.05 & 67 \\
\hline
\end{tabular}

